\title{
$-0$ \\ US and European Household Debt and Credit Constraints
}

Jonathan Crook'

Stefan Hochguerte/2

1 University of Edinburgh;

2 VU University Amsterdam, and Tinbergen Institute. 


\section{Tinbergen Institute}

The Tinbergen Institute is the institute for economic research of the Erasmus Universiteit Rotterdam, Universiteit van Amsterdam, and Vrije Universiteit Amsterdam.

Tinbergen Institute Amsterdam

Roetersstraat 31

1018 WB Amsterdam

The Netherlands

Tel.: $\quad+31(0) 205513500$

Fax: $\quad+31(0) 205513555$

Tinbergen Institute Rotterdam

Burg. Oudlaan 50

3062 PA Rotterdam

The Netherlands

Tel.: $\quad+31(0) 104088900$

Fax: $\quad+31(0) 104089031$

Most TI discussion papers can be downloaded at http:/ /www.tinbergen.nl. 


\title{
US and European Household Debt and Credit Constraints: Comparative Micro Evidence from the Last 15 Years
}

\author{
Jonathan Crook \\ University of Edinburgh \\ Stefan Hochguertel \\ VU University Amsterdam \\ Tinbergen Institute
}

Version: 12 November 2007

\begin{abstract}
This paper uses micro data from four OECD countries (the United States, Spain, Italy, and the Netherlands), to assess the determinants of household debt holding and to investigate whether or not credit constraints are important for household debt holding. We extend the existing literature in important ways. First, we present comparative evidence for four countries at the micro level, where we rely on household panel data for two countries; we are thus able to control for unobserved heterogeneity via individual household effects and to track changes in household behaviour over time. Second, by making data across countries as comparable as possible, we can explore the importance of the differences in institutional settings for debt incidence, debt outstanding and credit constraints. We also explore the implications for debt holding from consumption models, including a numerically solved precautionary savings model. We find that inter-country differences are substantial and remain even after controlling for a host of observable characteristics. This points to institutional differences between the countries being important.
\end{abstract}

Acknowledgements: This paper was written while the authors were visting the Finance and Consumption in the European Union Program at the European University Institute in Florence. We thank Finance and Consumption for their support and hospitality. Crook would also like to thank the Carnegie Trust for the Universities of Scotland for financial support for this research. We thank Rob Alessie, Richard Disney, Rob Euwals, Tullio Jappelli, Tansel Yilmazer, Ernesto Villanueva, seminar audiences at CPB The Hague, Universities of Copenhagen, Edinburgh, and Nottingham, and conference audiences at Vienna (European Economic Association), Florence, and Madrid for insightful comments. We thank Centerdata for providing Dutch panel data, and in particular Klaas de Vos for help with wealth data.

Correspondence to: jonathan.crookeed.ac.uk and shochguertelefeweb.vu.nl. 


\section{Introduction}

After the summer of 2007, credit to households has shifted into the focus of policymakers and the banking industry alike. What began with rising default rates in the US subprime mortgage market, may develop into a global credit crisis. European banks already face the consequences of borrowers being unable to service their contracts on time. In turn, central banks see their scope of action severely constrained, and the macroeconomic implications of these recent developments may be very farreaching.

Against this background, we provide a systematic international comparison of household debt holding and of access to credit, using microeconomic data that allow us to trace the evolution of debt and to assess constraints over the past one-and-a-half decades. Whilst current media attention is directed at whether access to borrowing has been too easy for some households, the academic literature has debated for a long time whether financial markets institutions may have inefficiently constrained household borrowing, and whether policy ought not to remove or ease such constraints.

Household debt holding has indeed increased substantially over the last decades in many OECD countries, both in terms of the total amount outstanding and relative to incomes, household debt portfolios have become more diversified. Have borrowing constraints become a non-issue?

We argue in this paper that this is not necessarily the right conclusion, based on analysis and comparison of micro data on household debt holding from four OECD countries that display very different patterns of debt holding and where credit constraints seem to play very different roles. Whereas we do find strong time trends, between-country differences remain very stark and appear empirically more important than within-country changes over time. These pertinent patterns suggest that institutions that shape demand and supply in credit markets play an important role, and we document substantial institutional differences between countries.

Very few studies have examined international differences in the volume of household debt or in credit constraints. Jappelli and Pagano (1989) started by analysing any excess sensitivity of consumption expenditure to current income in an international comparison. They interpret their findings in the light of institutional differences across seven countries, and relate implied differences in the demand and supply of loans to variation in the severity of liquidity constraints. Bacchetta and Gerlach (1997) used aggregate data for five OECD countries to find that overall consumption expenditure shows excess sensitivity with respect to both mortgage and consumer credit and that the wedge between borrowing and lending rates is significantly related to consumption in three of the five countries.

But the aggregate data employed say nothing about heterogeneous responses in the population to policy variation and changes in demand and supply conditions. Most empirical results based on micro data relate to the United States (Jappelli 1990, Crook, Thomas and Hamilton 2001, Duca and Rosenthal 1993, Lyons 2004, Cox and Jappelli 1993, Ferri and Simon 2002) although there is some research for Italy (Fabbri and Padula, 2004 and Magri 2002) and also for Australia (La Cava and Simon 2003). 
Several researchers have examined the determinants of household demand for debt and again the only countries considered are the US and Italy (see Crook, 2006 for a survey). The single-country evidence suggests that the incidence of credit constraints differs considerably between countries.

This paper has two main aims and contributions. First, we compare the determinants of household level credit constraints across four OECD countries over the last 15 years: the United States, Spain, Italy, and the Netherlands. We use panel data for the latter two and repeated cross sections for the United States. We also present the first evidence on debt and credit constraints from the first wave of a new Spanish survey. The micro data that have been analysed so far are typically not longitudinal and no study has yet provided international comparisons of the determinants of credit constraints and the demand for household debt using micro data directly. The data we use have gained international recognition for being among the most reliable sources for measuring household assets and liabilities. We expend large efforts to make the data as comparable as possible in terms of variable definitions, and we document common trends. In all countries we rely on self-reports on whether or not households' credit applications have been turned down or whether households felt discouraged from applying for credit. Second, our results bear on parts of the consumption literature, as we find strong patterns in the data that are consistent with standard models deriving from the permanent income hypothesis. To be specific, we find the demand for credit to respond negatively to an increase in a positive difference between current and (a measure of) permanent income in two of the four countries.

The remainder of this paper is structured as follows. In Section 2 we sketch and numerically solve a consumption model that allows us to explore determinants of the demand for credit in the face of credit constraints. In Section 3, we discuss the way in which institutions may impact on observed credit behaviour (both demand and supply), and we discuss in detail institutional differences between countries. Section 4 introduces the data used, and Section 5 describes the distribution of debt outstanding in the different countries. Section 6 sketches empirical strategies, Section 7 briefly comments on estimators used and presents results on credit application, credit constraints, and household debt holding. Section 8 concludes.

\section{Theory of Credit Constraints}

We consider the standard intertemporal choice framework to make clear how liquidity constraints can be important determinants of household credit behaviour. We start without such constraints. A consumer allocates his life-time earnings to consumption expenditure $c_{t}$ over time. Under intertemporal separability and exponential discounting, he maximizes the value function at age $t$ and with horizon $T$,

$$
V_{t}=E_{t}\left[\sum_{s=t}^{T} \beta^{s-t} u\left(c_{s}\right)\right]
$$

where $E_{t}$ denotes the expectations operator conditional on information at time $t, u$ denotes instantaneous felicity and $\beta$ is a factor used to discount the future with $\delta$ being the rate of time preference, $\beta=(1+\delta)^{-1}$. Denote (stochastic) earnings by $y_{t}$. 
There is a single asset $A$ with a single, fixed return $R=1+r$. The behavioural equation that drives consumption demand and implies asset and debt holding is the Euler equation

$u^{\prime}\left(c_{t}\right)=\beta R E_{t} u^{\prime}\left(c_{t+1}\right)$

The level of consumption is determined from here together with a constraint on assets in the final period. We assume $A_{T}=0$. Absent further restrictions on either utility or income processes (or both), closed form solutions for optimal consumption do not exist.

Under the parameterization of the Certainty Equivalence version of Friedman's permanent income hypothesis (PIH), some explicit solutions have been derived (see e.g. Deaton, 1992). Here, consumers' time preference rate equals the interest rate, $\beta R=1$, and instantaneous felicity functions $u$ are quadratic in consumption. In that case, marginal utility is linear and consumption follows a martingale, $c_{t}=E_{t} c_{t+1}$. A closed-form solution for optimal consumption can be obtained. Consumption will equal permanent income, $Y_{t}^{p}$, which is defined to correspond to the annuity value of future earnings and capital income. Kapteyn, Alessie and Lusardi (2005) show the dependency of current assets on income realizations and expectation errors:

$$
\begin{aligned}
& A_{t}=R^{t}\left(A_{0}+\left[\sum_{s=1}^{t} R^{-s} E_{1} y_{s}\right]+\left[\sum_{s=1}^{t} R^{-s} \varepsilon_{1 ; s}\right]-\left[\sum_{s=1}^{t} R^{-s} Y_{s}^{p}\right]\right) \\
& =R^{t}\left(A_{0}+\sum_{s=1}^{t} R^{-s}\left\{E_{1} y_{s}+\varepsilon_{1 ; s}-Y_{s}^{p}\right\}\right)
\end{aligned}
$$

where $\varepsilon_{1 ; s}=y_{s}-E_{1} y_{s}$ is the period-1 expectation error of period-s income. This equation shows how unexpected deviations from income translate into asset or debt changes. The notional demand for debt arises out of $A_{t}<0$. With a hump-shaped earnings profile over the life cycle, a household would be expected to borrow when relatively young and dissave in retirement. Since an unexpected change in income will affect permanent income only by its annuity value, borrowing is more sensitive to income shocks than consumption. The latter reacts mainly to permanent shocks, the former also to transitory shocks.

To illustrate further, assume that income is certain and grows at factor $G$ between the years, until before retirement, $y_{t}=G^{t-1} y_{1}, t=1, \ldots, t_{R-1}$, and drops to a constant fraction of last earnings $y_{t}=\alpha y_{t_{R}-1}, t=t_{R}, \ldots, T$ in retirement. Then, assets (and hence debt) can be shown to evolve according to

$$
\begin{aligned}
& \kappa A_{t}=\left(1-R^{t-T}\right) A_{0}+\frac{y_{1}}{r-g}\left(\kappa\left(R^{t}-G^{t}\right)-\left(R^{t}-1\right)\left[1-\left(\frac{G}{R}\right)^{t_{R}-1}\right]\right)- \\
& \left(R^{-T}+R^{t+1-t_{R}}-R^{1-t_{R}}-R^{t-T}\right) \frac{y_{1} \alpha G^{t_{R}-2}}{r}, t \leq t_{R}-1
\end{aligned}
$$




$$
\kappa A_{t}=\left(1-R^{t-T}\right)\left\{A_{0}+\frac{y_{1}}{r-g}\left(1-\left(\frac{G}{R}\right)^{t_{R}-1}\right)\right\}-\left(1+R^{t+1-t_{R}-T}-R^{1-t_{R}}-R^{t-T}\right) \frac{y_{1} \alpha G^{t_{R}-2}}{r}, t \geq t_{R}
$$

where $\kappa=\left(1-R^{-T}\right)$.

Since incomes are smooth during both working and retirement periods, assets will be smooth functions as well. Further assume the absence of inheritances, $A_{0}=0$. The model still allows for a number of very different asset paths, among which an initial period of borrowing, followed by positive assets that peak at the beginning of retirement and are then run down. Other scenarios are possible, including a household never borrowing or never having positive assets. Comparative statics can in principle be obtained by taking the derivatives with respect to the various parameters. While increasing retirement age or the replacement rate will reduce asset holdings (since there is less need to save for retirement), the demand for debt holding will increase. Income growth will likewise increase the demand for debt. If income growth is sufficiently small or zero during working life, no debt will be held. (Income growth is nonpositive between periods $t_{R-1}$ and $t_{R}$ due to $\alpha \leq 1$ ). Further insights can be gained by solving the model numerically, or by further restricting some of the model's parameters.

Credit constraints in the sense that consumers are kept from borrowing despite their wanting to borrow at the given interest rate enter the model by adding additional lower bounds on current assets, $A_{t} \geq-B$ for every $t$, where $B \geq 0$ is the borrowing limit. If $B$ is zero, no borrowing is possible, if $B>0$, borrowing is possible against human capital to the extent that the loan is not collateralized. These rationing constraints have been motivated by Stiglitz and Weiss (1981) from problems of asymmetric information. Competitive banks turn out to have an optimal interest rate if they are to maximize their rate of return on their lending portfolios. Taking into account the effects of adverse selection, a high enough lending rate will price the good risks out of the market, leaving the pool of borrowers dominated by worse risks (who might have a larger probability of defaulting on their loans). The optimal lending rate is set where the marginal cost incurred due to adverse selection balance off against the incremental profit that is possible with setting a higher rate. Sticking to this optimal rate may involve rationing of demand in equilibrium, and some borrowers will not be granted their loan applications despite them being observationally equivalent to others, given the interest rate.

In consumption models, credit constraints are imposed as additional inequality constraints on the problem. Deaton (1991) writes the Euler equation as

$u^{\prime}\left(c_{t}\right)=\max \left\{u^{\prime}\left(x_{t}\right), \beta R E_{t} u^{\prime}\left(c_{t+1}\right)\right\}$

where $x_{t}=A_{t}+y_{t}$ is cash on hand. Note that borrowing constraints imply not only breaking the usual Euler equation between two periods when rationing is binding, but 
there is also an anticipatory effect on consumption (and hence borrowing) since liquidity constraints that may bind in the future can work through on present behaviour and encourage saving or reduce borrowing. Mariger (1987) stresses that such constraints effectively shorten the planning horizon. Figure 1 illustrates: the solid line shows consumption and assets in the absence of credit constraints, the dashed line imposes a nonzero borrowing limit: consumption smoothing leads to the effective period of binding constraints to be shorter than would have been the case if the consumer had been 'surprised'.

\section{FIGURE 1 HERE}

More general models allowing for nonlinear marginal utility, such as constant relative risk aversion

$$
u\left(c_{t}\right)=\frac{c_{t}^{1-\gamma}}{1-\gamma}
$$

(where $\gamma$ measures risk aversion) imply that preference parameters whose impact the certainty equivalence formulation from above ignores are crucial determinants of borrowing behaviour (Carroll, 1997 and Deaton, 1991). If consumers are patient enough and sufficiently risk averse (thus, have a low elasticity of intertemporal substitution), they may be less inclined to borrow or would not want to borrow at all. In addition, as stressed by Carroll (1997), the stochastic properties of the income process will matter: If income can drop to zero with positive probability, even impatient consumers with steep income profiles may not want to borrow in order to avoid (in utility terms) 'catastrophic' outcomes. Since closed-form solutions are not available, we need to simulate the model in order to study the implications of parameter values and changes thereof. Income consists of the current realization of permanent income and a multiplicative transitory income shock $\varepsilon_{t}$. Note, that permanent income is - unlike in the certainty equivalence case-varying over time. Permanent income is modelled as an $\mathrm{AR}(1)$ process; it grows at rate $G$ and is subject to a permanent $\operatorname{shock} \eta_{t}$,

$$
\begin{gathered}
y_{t}=Y_{t}^{p} \varepsilon_{t} \\
Y_{t}^{p}=Y_{t-1}^{p} \eta_{t}
\end{gathered}
$$

Shocks are assumed to be lognormally distributed, with parameters $\sigma_{\varepsilon}$ and $\sigma_{\eta}$ (and $\mu_{\varepsilon}=-0.5 \sigma_{\varepsilon}^{2}$, and $\mu_{\eta}=-0.5 \sigma_{\eta}^{2}$,). The model can be solved numerically by backward induction, where we determine the optimal consumption policy as a function of current cash-on-hand (see Deaton 1991 for details). Note, that standard references in the literature assume $T \rightarrow \infty$ for computational purposes. Since that implies absence of a retirement period, we solve the model for finite $T$. Individuals retire at a fixed date $t_{R}$, upon which their incomes drop to a fraction $\alpha$ of their last earned income. The latter however implies that known comparative statics are not available anymore, not least because income growth is negative at $t_{R}$ and zero thereafter. We study the model under absence and presence of an explicit borrowing constraint at $B=0$. 
Benchmark parameters are shown in Table 1, chosen in accordance with similar exercises done elsewhere in the literature. Table 2 shows debt holding patterns for this benchmark case and for cases where we deviated from the benchmark parameters by changing one parameter at a time since often a range of parameter values appears 'sensible'.

\section{TABLE 1 HERE}

\section{TABLE 2 HERE}

All specifications show common patterns. For instance, the ratio of average debt to average income is slightly smaller than the mean of the individual debt to income ratio. The distributions of debt to income, both unconditional and conditional (on debt holding), are right skewed, and in (almost) all cases we observe a hump-shaped age pattern: the 40 year olds appear to hold most debt among all the displayed ages. The standard deviation of debt to income also peaks at age 40 or 50 . This is driven by the generated heterogeneity due to income uncertainty in the model. Debt incidence is almost always monotonically decreasing with age. In addition, debt holding in retirement is rare and surfaces only in a few instances.

The benchmark specification shows a decreasing age pattern in terms of debt incidence, with people of 30 years of age having an $81 \%$ chance of debt holding, decreasing to zero in retirement. At age $40,73.4 \%$ of all individuals hold debt. Average debt holding amounts to about a quarter of annual income (both at the aggregate and individual level). Conditional on holding debt, the figure exceeds one third at that age. Note that in this benchmark case conditional debt holding increases when we go from age 50 to age 60. Apparently, the sample is then dominated by a few people that hold high debt balances.

We also recalculate the model for the case that binding liquidity constraints at a lower bound of $B=0$ are imposed. If we define people to be constrained when their current cash on hand falls short of 110 percent of their consumption level at that age, we see that $17.6 \%$ of the 30 year olds are constrained as opposed to $2.5 \%$ of 40 year olds. This should be contrasted with the $81.1 \%$ and $73.4 \%$ of people that want to hold debt at these ages. Note that the difference between these figures is partly driven by the precautionary response: people that are liquidity constrained will want to build up additional buffers to stay away from the constraint. Thus, when people anticipate liquidity constraints in the future, they will be induced to save more and be less inclined to apply for credit (in this model, under a binding liquidity constraint, everybody who wants credit will also be denied).

Deviating from the benchmark shows interesting patterns. The second panel of the Table considers cases where the retirement saving motive is varied. Decreasing the retirement replacement rate from $75 \%$ to $65 \%$ of last earned income reduces debt holding substantially. Even more remarkable, however, is the sensitivity of changes with respect to income growth. Reducing income growth from $2.0 \%$ to $1.5 \%$ percent slashes the demand for debt to close to zero. Conversely, increasing income growth to $2.5 \%$ would result in almost every young household holding debt (not displayed in the Table). 
The third panel of the Table looks at changes in the precautionary response. We make either income less volatile, reducing the standard deviation of income shocks from $10 \%$ to $7.5 \%$, or we increase the curvature of marginal utility, by increasing risk aversion from 2 to 3 . The former change increases debt holding by a large margin, the latter likewise decreases it. The effect of the change in risk aversion is comparable to the effect of the change in income growth.

The last panel, finally, varies the return on assets and the time preference rate, one at a time. Increasing the interest rate has again quantitatively similar effects as decreasing income growth or increasing risk aversion. The result is not straightforward to interpret, however, since there are at least three effects at work. A substitution effect makes future consumption more attractive, thus stimulating saving, which may be partly offset by an income effect that raises future wealth through the return on assets (if assets are positive). Also, there is a human capital effect that reduces the present value of lifetime earnings, depressing consumption and stimulating asset accumulation. Finally, making the consumer more impatient has the anticipated result that debt holding increases substantially.

\section{Prima Facie Evidence and Institutional Differences between Credit Markets}

The previous section outlined how parameters of a consumer's problem impact on the demand for credit and the likelihood of being credit constrained, once there are exogenous borrowing constraints. Yet, we expect and show below that there are substantial differences between countries remaining that are not easily explained by changes in those parameters.

Instead, institutional factors (which the above model does not include) are likely important determinants of both supply and demand for debt, the incidence of holding debt and the incidence of credit constraints. Hence our strategy is similar to that of other studies that examine patterns between countries, such as Banks, Blundell and Smith (2003), Hurd and Kapteyn (2003), Kapteyn and Panis (2003), or Börsch-Supan and Lusardi (2003) in that we implicitly attribute the unexplained variation between countries to differences in institutions.

This section discusses these factors and their implications, referring to the four OECD countries under study: the United States, Spain, Italy, and the Netherlands.

There are three reasons why we choose these countries. Most importantly, there are substantial institutional and structural differences between these countries and so a comparison between them may give us a first idea as to the effects of these institutional differences. Second, there are substantial differences in the use of credit between the countries, some of which marking extremes within the OECD. Third, purely pragmatically, these are the only four countries for which a nationally representative survey collects data for self-reported credit constraints (Crook 2005).

To illustrate the second point, refer to Table 3 presenting OECD data. The Netherlands is one of the highest consumer debt-laden countries in Europe and the western world whilst Italy is one of the lowest. The US is in this respect 'closer' to the Netherlands than to Italy. Spain, in turn, ranks just below the US. For example, of all 
OECD countries for which data is available in 2005, the Netherlands had the secondhighest level of household debt (including non-profit institutions) relative to disposable income (134\%) whilst Italy had the lowest at $43 \%$, the US ranked fourth with $111 \%$, and Spain fifth with $94 \%$. In terms of mortgage debt relative to GDP, the Netherlands has amongst the highest ratio in the world. The Dutch figure almost doubled from around $40 \%$ beginning of the 1990's to $78.8 \%$ recently. Italy is at the other extreme, where mortgage levels did not exceed $5 \%$ during much of the last two decades, with increases to $11.4 \%$ only recently (2002). The US and Spain are in between - the mortgage-to-GDP ratio used to be highest among the three countries in the US (around 45\% around a decade ago), but has not seen as steep increases as Holland (58\% in 2002). Spanish mortgage debt relative to GDP has seen the most spectacular growth as figures almost tripled between 1992 and 2002, from 12\% to $32 \%$. These (and similar) statistics suggest that these four countries span much of the between-country differences in debt holding in the OECD.

\section{TABLE 3 HERE}

In the remainder of this section we give a brief overview of institutional and structural factors that may result in differences in demand and supply (and so the volume) of debt held by households between the four countries. There is an array of potentially important institutional determinants, ranging from the way financial markets deal with problems of asymmetric information to provisions in the tax code to deduct interest payments on debt held. But also the organisation of the welfare state and consumers' attitudes and perceptions may bear importantly on consumption behaviour and the derived demand for debt.

\subsection{Social Income Insurance and Perceptions of Income Risk}

Both Italy and the Netherlands value social security highly, albeit with different implementations of the social insurance and welfare state. Italy puts a strong emphasis on state old-age pensions, while spending very little on unemployment insurance, whereas the Netherlands spend a comparatively large share of their social budget on disability insurance (that partly masks long-term unemployability). For example, from OECD figures (Social Expenditure Database) we calculate that unemployment spending during the period 1990-2001 was on average $2.3 \%$ of GDP in the Netherlands, $2.2 \%$ in Spain, $0.9 \%$ in Italy and $0.4 \%$ in the US, with the maximum duration for such receipts being five years in the Netherlands, two years in Spain, but only six months for Italy and the US. European countries know extensive national health care systems (with more emphasis on income-related private health insurance in the Dutch case). In the US, state pensions will make up most of social security. See Kapteyn and Panis (2003) and Börsch-Supan and Lusardi (2003), for more detail. Employment protection legislation is most stringent in Spain, followed by Italy and the Netherlands, least in the US. ${ }^{1}$

\footnotetext{
${ }^{1}$ According to the OECD Employment Outlook 2004, the US receives an index value of 0.7 on a 0-6 scale overall employment protection index and ranks last among 28 countries. Italy and the Netherlands have index numbers of 2.4 and 2.3 and rank 11 and 12, respectively, Spain ranks fourth with 3.1. Generally, laying off workers is comparatively easy in the US and relatively difficult in all the European countries. Yet, a substantial number of Spanish employees finds work via temporary contracts, whereas the Italian labour market is characterized by longer employment relations. Owing to institutional differences in wage setting, there is also much larger wage compression in European
} 
The design and coverage of social insurances would imply a greater demand for debt for purposes of temporary consumption smoothing in the US compared to the Netherlands and finally, Spain and Italy. Similarly, ceteris paribus, with more employment security in Spain and Italy than in the Netherlands and the US one would expect the supply of credit to be in this rank order.

Note, however that demand for credit for smoothing purposes also will depend on the perceived income uncertainty of consumers. Das and Donkers (1999) compare European (Italian and Dutch) estimates of subjective perceptions of income uncertainty with those of the US and find perceived income uncertainty in the Netherlands to lie between that reported in Italian and US studies. Guiso, Jappelli and Pistaferri (2002) focus on perceptions of unemployment risk instead. They, however, find the US and Italy 'surprisingly similar' in terms of the distribution of subjective unemployment probabilities. There is, to our knowledge, no comparative evidence for Spain on this matter.

\subsection{Bankruptcy Legislation and Usury Regulation}

Bankruptcy legislation can act as wealth insurance against adverse shocks and hence increase the demand for credit. Italian bankruptcy legislation (unchanged since 1942) does not have formal provision for a consumer to be discharged from bankruptcy, unless creditors accept his proposals for repayment. Spain has introduced a new bankrupty act coming into force per September 2004 and covering natural persons; the law does not explicitly refer to consumer bankruptcy, however. Likewise, in the Netherlands discharge from bankruptcy for natural persons was not possible before 1998. After that date, discharge was allowed, conditional on adhering to a courtapproved repayment plan lasting 2 or 3 years. In the US, a debtor can choose between declaring bankruptcy under Chapters 7 or 13 of the Federal Bankruptcy Act. Under the former, unsecured debts are discharged, the debtor turns over all assets to a Trustee but is not obliged to repay debts out of future earnings. Under Chapter 13 a debtor does not give up his assets but must propose a repayment plan acceptable to the debtors or a bankruptcy judge. Proposed repayments under Chapter 13 must be at least as much as under Chapter 7. While these differences may point to higher demand for debt for US households, supply may likewise be larger than in Italy or the Netherlands: White (2006) argues that the higher the exemption the higher the protection, the lower the chance of default and the greater the supply of credit. Exemptions are higher in the US than in Italy and the Netherlands. ${ }^{2}$

countries as opposed to the US. Bertola and Rogerson (1997) investigate labour market turnover and wage compression in a number of countries, among which Italy and the US.

${ }^{2}$ Note that empirical evidence for the US is equivocal as to whether an applicant is more likely to be turned down for credit in States where exemptions are high. Gropp et al. (1997) and Lin and White (2001) suggest they are, Berkowitz and Hynes (1999) suggest the opposite. Gropp et al. (1997) suggest that lenders increased supply to satisfy greater demand by high asset households in high exemption States, but did not increase supply to low asset households. If this were generalisable across countries, it would suggest that in the US there would be greater supply and demand by high asset households than in Europe, but that supply in the US would not be greater than in the European countries for low asset households. 
Usury laws that cap the interest rate a lender is allowed to set may be expected to remove or reduce the insurance facility for temporary income shocks that consumer borrowing provides (Glaeser and Scheinkman 1998), to reduce the supply of loans to high-risk applicants (Canner and Fergus 1987, Villegas 1989, Baxter 1995) and to reduce the extent of adverse selection and moral hazard. Yet, such limits appear to be of little practical importance in the 1990s in any of the countries under study. Usury limits were effective in many US States, in Spain, in the Netherlands, and (introduced in 1997) in Italy. However, these limits were typically too high to be binding (see Alessie, Hochguertel and Weber (2005) for the Italian case).

\subsection{Judicial Enforcement and Information Sharing}

The cost of lending, and with it the supply of loans is to some extent explained by the cost of recovering the principal from delinquent borrowers. The more efficient the judicial system to deal with such cases, the lower the cost. Djankov, La Porta and Lopez-de-Silanes (2003) report the duration of dispute resolution for two clinical court cases: collecting a bounced check and evicting a delinquent tenant, for 109 countries. Their data convey that for the check case, Italy ranks 106 (645 days), Spain ranks 39 (147 days) Netherlands ranks 4 (39 days), the US ranks 7 (54 days); for eviction, Italy ranks 101 (630 days), Spain ranks 51 (183 days), the US ranks 7 (49 days), the Netherlands rank 9 (52 days).

Similarly, the data presented in Bianco, Jappelli and Pagano (2005) show a close similarity in terms of judicial efficiency between the Netherlands and the US at one end of the spectrum, and Italy and Spain on the other. Italy and Spain have long foreclosure proceedings on mortgages and low judicial efficiency along with a low ratio of mortgage debt to GDP and a high downpayment ratio, the reverse holding true in the Netherlands and the US.

Jappelli and Pagano (2002) assess the depth of credit information sharing across many countries, accomplished by credit bureaus. These issue on average 2.3 reports per citizen per year in the US, 0.64 in Holland, and 0.046 in Italy. Data on Spain are not available. Both positive (outstanding debt and number of credit, assets held, bank relationships and so forth) and negative (repayment delinquencies, default, arrears) information are collected by such agencies. Since information sharing may limit adverse selection and moral hazard, and also increase competition, the Italian credit market may be characterized as being relatively inefficient. However, credit bureaus are partly substituted by public credit registers that have existed in Italy since the 1960s and in Spain since the 1980s (and do not exist in the US or in the Netherlands).

\subsection{Homeownership and House Price Developments}

With the demand for consumer debt being driven by the demand for durable and nondurable consumption, developments in ownership rates and prices of the underlying assets (or durables) will play an important role. Home ownership in the Netherlands has been increasing steadily from about $42 \%$ in 1980 , to $45 \%$ in 1990 , and to about $53 \%$ in recent years. This level is low in international comparison, but implies that the flow into home ownership relative to the stock is important. The US traditionally has 
a home ownership rate of about two thirds, with an upward trend over the last decade (from about 64\% in 1990 to about 68\% in 2002). Italy's home ownership rate has also increased substantially, from $59 \%$ in 1980 to $68 \%$ in 1990 and to about $80 \%$ in 2002 . Spain has had traditionally the highest homeownership rate among our countries with $78 \%$ in 1990 , rising to about $85 \%$ in 2002.

Yet, these changes do not translate one for one into house price changes. Whereas the Netherlands, Spain and the US have seen house price booms over the last decade, Italy experienced declines in real house prices during most of this period, see Allen, Chui and Maddaloni (2004). While the Dutch house price boom decelerated in the last couple of years, Spanish data reveal a continuing, two-digit annual rise until recently. If a rise in house prices is interpreted as a permanent change to net wealth, homeowners may want to boost nondurable consumption by means of home equity withdrawal. Secondly, first-time buyers may have a higher demand for mortgages after house price increases (unless they are discouraged). Along with these developments, mortgage debt outstanding is highest in the Netherlands, whereas the highest growth in mortgage debt to GDP is seen in Spain (recall Table 3). These patterns are consistent with mortgage debt in Spain and Holland being driven by price increases while it is determined by changes in home ownership in Italy. In addition, home equity withdrawal relative to disposable income mirrored the level of house prices for both the Netherlands and US. In Italy and Spain, in aggregate, home equity withdrawal did not occur. But the excess of net lending secured on dwellings over investment in them became closer to zero whilst house prices declined in Italy and it stayed fairly constant whilst house prices rose rapidly in Spain (Allen, Chui and Maddaloni 2004). One possible explanation is that a greater proportion of homeowners in the US and Netherlands are credit or liquidity constrained than in Italy or Spain; another is that collateral differs in importance between the former two countries and Italy because of differences in judicial costs.

\subsection{Mortgage Market Institutions}

While house prices and home ownership will explain some of household debt holding, other characteristics of the mortgage market may be important. ${ }^{3}$ After all, the incidence of mortgages among Dutch households is highest despite the homeownership rate being lowest among all our four countries. Down payment ratios are typically significantly higher in Italy (42\% in 1991-95) than in the Netherlands (25\%), Spain (20\%) or the US (11\%) (Bianco, Jappelli and Pagano 2005). Conversely, the loan-to-value ratio tends to be low in Italy on average (55\%), higher in Spain (70\%) and in the US (78\%) and highest in the Netherlands (90\%). Maximum values will depend on individual lenders, but the average maximum will again be much larger in the Netherlands (110-115\%, depending on sources) than in Italy (up to $80 \%)$ or Spain $(100 \%)$.

Further, transactions cost such as legal expenses paid as a proportion of the mortgage house price are higher in Italy (18-20\%) than in the Netherlands (11\%). The OECD (2004) suggests that administrative costs of liquidation are also higher for Spain than for the US, and higher again than for the Netherlands. Also, penalties on early

\footnotetext{
${ }^{3}$ Bianco et al. (2005), Allen et al. (2004), Low et al. (2003) and Chiuri and Jappelli (2003) report on these.
} 
repayment of mortgage debt differ between countries. Low, Sebag-Montefiore and Dübel (2003) report for the Netherlands that in practice about $15 \%$ of the loan outstanding is prepayable without fee, whereas in Italy a fee is charged amounting to 1 to $2 \%$ of the capital repaid. Prepayment fees in Spain are reported not to exceed $2.5 \%$.

Of further importance for mortgage demand are the typical term of a mortgage (30 years in the Netherlands and the US, 20 years in Spain and 15 years in Italy), and the period of fixed interest rates (in the US, Spain and in Italy, mortgages are typically of the fixed-interest type, whereas in Holland only an initial period of, say, about 10 years is fixed-interest). Finally, some loans in the Netherlands are subject to the government national mortgage guarantee scheme which underwrites the loan to the lender so reducing the lender's risk and consequently interest rates.

\subsection{Financial Systems and Financial Liberalization}

Throughout the 1990s there was no restriction on the regional ownership of banks in our European countries. In the US, prior to the Reigle-Neal Act of 1994, multistate bank holding companies had to apply to each State for permission to own a subsidiary bank in that State. The Act removed this requirement with the effect that many mergers between bank subsidiaries in different State occurred and new braches opened. Evidence by Welan (2000) indicates that this improved competition for deposits and we might consequently expect also an easing of constraints to borrowers. It may also have increased the use of risk-based loan pricing. In addition, credit scoring technologies are more likely to have been passed between banks in different States.

Low, Sebag-Montefiore and Dübel (2003) characterise Italian mortgage lenders as having high relative costs due to lack of automation and lack of economies of scale. Regulations prevent branch closures. Margins are relatively high but entry by foreign banks is reducing them. In contrast, lenders in the Netherlands are more efficient, but again competition and fees paid to introducers are lowering margins. Spanish mortgages are characterised as being subject to increased price competition, while entry of foreign competitors may be limited due to providers' cost in dealing with registration and repossession laws, and inefficiencies in information sharing. In general, forces of European integration are seen to benefit competition in all the European countries, however.

\subsection{Taxes}

The four countries also differ in the tax deductibility of debt interest. Both the Netherlands and the US used to have consumer credit interest tax-deductible, along with mortgage interest, while Italy never had this provision for non-mortgage debt. Tax reforms have changed the picture, however. The US 1986 Tax Reform Act, and similarly the Dutch 2001 reform of Income Tax phased out deductibility of consumer credit interest (see Maki (2001) for the US). Both the US and Dutch tax reforms make the purpose of the loan decisive for tax-deductibility: the latter applies only where the loan is used for investment (including maintenance) in the primary residence, and irrespective of loan type. Holland remains the only country with unrestricted deductibility of mortgage interest paid on the first primary residence. In the US, 
deductibility of "home equity debt" is further capped by a ceiling of $\$ 100,000$ outstanding per tax filer. In Italy before 1992 mortgage interest was fully tax deductible up to $€ 3500$. In 1992 the tax deduction was made a fixed percentage of the interest paid and this percentage decreased from $27 \%$ to $22 \%$ in 1997 and to $19 \%$ in 1998. However Jappelli and Pistaferri (2004) found that these changes did not alter the demand for mortgages by high income tax payers relative to other groups. Main reforms in tax code in Spain during the 1990s relate to reductions in tax deductions for secondary and rented dwellings. On the other hand, imputed income from owneroccupied housing is not subject to tax anymore.

\section{Data}

All four individual data sets are household surveys conducted under the auspices of national banks.

We use a household panel dataset for each of the Netherlands and Italy and repeated cross sectional household data from the US. For the Netherlands we analyse the DNB Household Survey (DHS), which is carried out annually and contains a sample of nationally representative households. This data set surveys households on their wealth, debt, and portfolio position, income, demographics, labour force participation and basic work characteristics, as well as a detailed list of questions concerning the occupied dwelling. Consumption or expenditure is not covered. In terms of overall data quality, Alessie, Hochguertel and van Soest (2002) assess the DHS data as reliable and reasonably good, with shortcomings on representing appropriately the lowest and uppermost percentiles of the wealth distribution. ${ }^{4}$ The data consists of two strata: a representative sample and a high-income sample. The former is representative of the entire residential population (except for institutionalised persons and households); the latter is included to represent the upper decile of the income distribution in $1992 .^{5}$

For Italy we use the Survey of Household Income and Wealth (SHIW), which has been carried out biennially since 1987, although its origins date back to 1965 . Comprehensive descriptions are given by Brandolini and Cannari (1994) and Guiso and Jappelli (2002). The sampling is in two stages: first municipalities are chosen from 51 strata from throughout Italy and then households are randomly chosen from registry office records within each chosen municipality. The panel component makes up $45 \%$ of the 1995 sample, $43 \%$ of the 1993 sample and $27 \%$ of the 1991 sample. Departing households from the panel are replaced. There is some imputation especially for wealth variables, but missing values remain. Our sample consists of the seven waves 1991-2004, covering 5,400 households in the initial wave and around 8,000 in the remaining ones. A larger proportion of the households surveyed were

\footnotetext{
${ }^{4}$ The DHS has been renamed a couple of times. Until 2002 it was called "CentER Savings Survey".

5 The representative sample is available for the years 1993 through 2006 with refreshment samples drawn every year to replace attriting participants; the high-income sample is followed without replacement and essentially is non-existent from the survey wave 1998 onwards. The representative sample has a size of about 2,000 households each year; the high-income sample initially covered 900 households. In terms of cross-sectional base, the DHS is the smallest of the three datasets we use, implying that the impact of sampling noise may be higher than in the other two surveys.
} 
discarded in 1991 than in other years because of particular difficulties in this year of gaining values for wealth.

For the US we use the Survey of Consumer Finances (SCF), the most reliable source of information on household assets and debts, administered by the Federal Reserve Board. There are various sources of descriptive material on the data, the most recent one being Aizcorbe, Kennickell and Moore (2003). The SCF is a repeated cross section triennial survey of households which is intended to be nationally representative of the distribution on net wealth in the US. The survey has a dual frame sample design: a multi-stage area probability sample and an oversample of high wealth households. The latter sample is drawn from a sample of tax files. The former typically make up around 2900 households and the latter around 1400 households. It is not possible to identify households in the high wealth over sample. All missing values have been imputed five times. In this paper we use data from 1992, 95, 98 and 2001 in our empirical modelling to be consistent with the chronological coverage for the Netherlands and Italy and because one of our covariates (age of children) is not discernable in the 2004 survey. We also use the first implicate only.

The data from Spain is drawn from the first wave (2002) of the recently launched Bank of Spain's Survey of Household Finances (EFF), which has been modelled after the SCF and also oversamples wealthy households which cannot be separately identified, although it does not probe household finances at quite the same depth. The data contains information from respondents in 5,143 households. Description and first quality assessment are available in Bover (2004). Similarly to the US data, the EFF includes multiple imputations of missing values, from which we use the first implicate.

The earliest data we use is for the early 1990s, for the following reasons: First, the Dutch data is available only from 1992 onwards; second the Italian data does not contain sufficient questions on whether a household is credit constrained to be usable in 1989, third the lack of data on financial assets in the Italian data would make estimates of wealth derived from it very imprecise and finally the panel component of the SHIW was very small in 1989. Moreover, household debt holding really underwent the largest changes in the past 15 years. $^{6}$

Important for our paper, all surveys contain comparable information on households' responses as to whether they were rejected or discouraged from applying for credit and whilst this is not the only possible measure of whether a household is credit constrained, we prefer such a measure over sample-splitting exercises along the financial asset distribution, as initially suggested by Zeldes (1989). We define a

\footnotetext{
${ }^{6}$ When referring to particular years, one remark is in order. In the tabulations to follow, a year label, such as "1995" can refer to different things. For instance, in the Dutch data it refers to the year when the interview was conducted, and hence to all measures of background characteristics and the like. Assets and liabilities (stocks) are measured as per 31 December of the preceding year, however, and incomes (flows) relate to the entire previous year. But for the SHIW and the EFF, income relates to the current year and the wealth variables to 31 December of that year. For the SCF income is measured for the previous year whereas assets and liabilities are measured as per the current year. As shall become apparent below, these definitional differences do not impact on the conclusions we draw from the empirical exercise.
} 
household as reporting being constrained or discouraged when at least one of the responding adult members reports this to be the case.

A common difficulty with international comparisons of household data is that many variables are measured differently between the countries and sometimes even within a country (survey) over time. The data Appendix defines the variables we have used in our analysis. Education deserves special attention due to the large institutional variation in educational systems between countries. The Table in the Data Appendix lists the six education categories that we can identify in all countries and that correspond to OECD (1999) classifications of educational degrees. All education variables refer to the highest qualification for which a degree was obtained.

Two further variables deserve comment. The income and age variables in the estimated equations are linear splines. The coefficient for each such variable represents the change in the dependent variable for a small change in income or age within that particular income or age range (see Appendix). The income spline knots were set to have six equally populated groups in each country in a particular year. Second, we included permanent income as the difference between current income and permanent income. The PIH argues that when this difference is positive, households will demand less debt believing their future income will fall and vice versa. For Italy and the Netherlands, where we have panel data, we estimated permanent income following the approach employed by Kapteyn, Alessie and Lusardi (2005). In this method, permanent income is found by estimating non-capital income at age $a$ at time $t+j, a_{t+j}$, for each age using a random effects model and then finding the annuity value of this assuming it is received up to age 65. For the US and Spain, where panel data are not available, we used the method of King and Dicks-Mireaux (1982). ${ }^{7}$ For purely empirical reasons (achieving a better for models fit to highly skewed data), we employ a log-type transformation on wealth, income and the difference between income and permanent income. ${ }^{8}$

\section{Debt Holdings}

We now turn to the patterns of household debt holding over time. Table 4 shows the incidence, mean and median household debt over all households in 1992 Euros for each country. ${ }^{9}$ The proportion of households with any form of debt (Table 4a) is around ten percentage points higher in the US than in the Netherlands and both are considerably higher than the percentage of Italian households with debt. The incidence in Spain is midway between that of the Netherlands and Italy. Of course, there are slight differences in the types of debt measured in the surveys. For example, to present figures for a run of years we have excluded loans from relatives and friends from the Italian data, but this in no way alters this conclusion. These relative proportions for the US, the Netherlands and Italy seem to have remained constant over the whole of the 1990s. The difference between the proportions of households

\footnotetext{
${ }^{7}$ We ignore cohort effects in any of the permanent-income calculations.

${ }^{8}$ The precise transformation employed is $x^{\prime}=\log (x+1)$ if $x \geq 0$ and $x^{\prime}=-\log (-x+1)$ if $x<0$. It is antisymmetric and preserves zeros and signs of $x$. It is an alternative to the inverse hyperbolic sine transformation that is occasionally used in related literature.

${ }^{9}$ Italy, Spain and the Netherlands introduced the Euro on January 1, 1999. We use the official changeover conversion rates from national currencies to Euro for Italy and the Netherlands, and for the US 1.1812 dollars per Euro. All amounts have subsequently been deflated to 1992 using national CPIs.
} 
with mortgages is even greater than for any form of debt. The percentage of US households having at least one mortgage is only slightly higher than the percentage of Dutch households. But these proportions are considerably higher than in Italy, where the percentage of households with a mortgage is around a quarter of that in the Netherlands and US, and Spain where the proportion is just over half that of the US. A similar pattern holds true for non-mortgage debt.

\section{TABLES 4a-c HERE}

If we consider trends within the US, Netherlands and Italy we can see that the proportion of households with any debt increased from the beginning of the decade until around 2000 and then seems to have decreased somewhat in Holland; in Italy the incidence has decreased slightly whereas the proportion of US households with any form of debt has remained fairly constant until around 2000 and then increased. However these trends in the holding of any form of debt mask differences between the countries when we look at specific types of debt. The proportion of households with at least one mortgage remained fairly constant in the Netherlands but seems to have decreased slightly and recently increased in Italy and it has consistently increased in the US. The percentage with other types of debt has decreased in the Netherlands over the years, whereas it remained roughly constant in the other two countries.

Not only do a smaller percentage of Italian and Spanish households hold debt, but the average amount of debt outstanding per household is considerably lower in the two Mediterranean countries than in either of the other countries, as Table $4 \mathrm{~b}$ shows. The average amount of debt per household in the US is ten times that in Italy, five times that in Spain and typically over 33\% higher than that owed by Dutch households. This difference is mainly due to the differences in mortgage debt held and less due to differences in non-mortgage debt. For example, in the first half of the 1990s and early in the 2000s the amount of non-mortgage debt-instalment loans, credit card debt, educational debt and so on-in the Netherlands was around twice that held by Italian households. Non mortgage debt held by Spanish households was very similar to that in Italy. All three were around one third of the debt owed by US families.

Of course, since the distribution of debt owed is very positively skewed, in Italy the median of total debt owed is zero. The same holds for the other countries for the lessprevalent subcomponents. Table $4 \mathrm{c}$ shows the median values of debt owed by those who have debt. This shows a subtly different picture. In the first half of the decade the median debt owed, by those who have debt was actually larger in the Netherlands than in the US, though this ranking is reversed by 2004. The median debt in Italy was around a quarter of that in the Netherlands with Spanish households holding an amount closer to Italian households than to Dutch households. Median mortgage debt increased much faster in the US than in Holland, however with the growth between 2001 and 2004 in the US being particularly large. The growth of median mortgage debt in Italy has also been rapid; it increased by over $110 \%$ in real terms between 1995 and 2004, but it was always between a quarter and a third of that for Dutch households. Only in 2005 and 2006 do we see conditional medians surging in Holland.

These differences are arguably caused by a combination of demand and supply factors. Table 5 investigates this further. This Table shows that the percentage of 
households that apply for any form of debt in Italy is considerably lower than the percentages in the Netherlands or Spain, which in turn are only a third of the percentage in the US. However, an immediate caution is necessary: the US figures show the proportion that applied for credit in the previous five years whereas the Dutch and Spanish figures relate to the previous two years and the Italian ones to the previous 12 months. Due to the unknown serial annual correlation at the household level in each country, we cannot simply divide the US figure by five and the Netherlands and Spain figures by two. However, within countries, we see that proportions stayed constant in the US in the 1990s and then increased considerably, whilst they have increased only moderately the Netherlands and have declined slightly in Italy.

\section{TABLE 5 HERE}

The proportion of applicants who are rejected by a lender is much higher in the US than in Italy, but higher in Italy than in the Netherlands and Spain. So, differences in debt incidence between the US and Italy or between the US and the Netherlands do not seem to be due to a higher reject rate in Italy or in the Netherlands. But the higher incidence in Spain than in Italy could be due to the lower rejection rate in Spain.

We can also compare the proportion of households who are either rejected or discouraged from applying for a loan over the decade as shown in columns 9-12 of the Table. But we must note that a household who is not rejected may either have applied and been accepted or may not have applied. These columns merely show the incidence of those households who have been rejected or discouraged. This percentage is ten times higher in the US than in Italy. The Dutch and Spanish figures are at low levels but higher than the Italian ones, and for Holland increase over time. So, if this measure is taken as indicative of whether a household is credit constrained then such constraints affect a much greater percentage of the US households than of Italian, Spanish or Dutch households.

Both the lower incidence of debt in Italy and the lower volumes of debt owed are consistent with the institutional differences between the countries which we noted in Section 3. Thus, part of the explanation for the lower debt in Italy is arguably due to the higher down payment requirements for house purchases (see Guiso, Jappelli and Terlizzese 1994). But this evidence is not consistent with the argument that the greater judicial costs in Italy are countered by Italian lenders only lending to lower risks than are accepted by lenders in the US, the Netherlands or Spain.

Of course part of the explanation for the differences in the incidence of debt may be that it is due to inter-country differences in household attitudes to risk, time preference rate, retirement income replacement rate, interest rate and/or income shocks, as Table 2 suggests. For example, the incidence of debt holdings is predicted to be lower if the income growth rate is lower, the interest rate is higher, households are more risk averse or the income replacement rate is lower.

Tables $6 \mathrm{a}$ and $6 \mathrm{~b}$ compare the characteristics of the heads of households that hold debt with those who do not. In the Netherlands there seems to be no large difference between the average age of those who hold debt and those who do not, whereas in Italy debt holders are nine years younger than those without debt, in Spain seven years 
younger and in the US debt holders are three years younger. In terms of many other household characteristics there is a clear pattern which is common to all four countries. Those households with debt have a larger family size, more children, are more likely to have a paid job, less likely to be retired, more likely to be self employed, less likely to be single, more likely to be married, less likely to be female and more likely to be better educated and on average have a higher income.

\section{TABLES 6a-b HERE}

As to the inter-country differences, the average age of the household head with debt in the Netherlands is slightly higher than in Italy, Spain and the US. The family size and number of children for those with debt is noticeably higher in Italy than in the Netherlands or the US. Among those with debt, the percentage that are self employed is much higher in Italy (around 23\%) than the US and Spain (around 12\%) and the Netherlands (around 5\%). Clearly, the national averages of self-employment are much higher in Italy than in the US, Spain and the Netherlands, but the comparison reveals that Italian self-employed are much more likely to be debtors than their Dutch, Spanish and American counterparts: there are almost twice as many self-employed in the Italian debtor sample compared to the overall sample, but only twenty percent more for the cases of Holland, Spain and the US. Substantial differences also occur between the US, Italy and Spain on the one hand the Netherlands on the other in the educational contrasts between those with and those without debt. The more highly educated households in the US, Italy and Spain are more likely to be debt holders than in the other two countries; the proportion of debt holding households with a degree is at least ten percent above that of those without debt for the US, Italy and Spain, but no different for Dutch households.

\section{Demand for Household Debt and Credit Constraints}

This section sketches an empirical approach to modelling observable data structures. We think of observed debt holding as resulting from a multi-stage decision process where notional demand, to the extent that it is positive, is potentially rationed by supply. The columns of Table 7 correspond to this layered structure.

\section{TABLE 7 HERE}

To begin with, households may or may not have a demand for debt or credit. For example the precautionary model predicts that those that do not may be at particular stages of their life cycle (for instance, retirees), they may be sufficiently patient, their incomes may perhaps not grow enough, or, perhaps less realistically, they might face real possibilities of total income loss (Carroll's income process). Such households will have a zero observed demand for credit. On the other hand, if one interprets desired demand for debt as a continuous variable it may actually be negative.

Those that want a positive amount of debt or credit may actually not apply for a loan because they are discouraged by the prospect of possible rejection. Whether or not such households have the right point expectations as regards their probability of being rejected is immaterial for our purposes; as a matter of fact, such households do exist. 
Conditional of not being discouraged, applicants with a positive demand for credit would apply for a certain loan. Those that are discouraged (and whose demand is positive by definition) will not apply for that same loan. (Of course, there may be people that are discouraged for one type of loan and not for some other). In other words, given a loan that a household with a positive demand can apply for, these two decisions are the same.

Those that apply may be rejected by the lender. The application may be entirely turned down, or it may be partly rejected in the sense that only part of the loan amount applied for is granted.

Summarizing, there are various ways to generate zero observed debt holding. Households with positive observed credit will need to want it, not be discouraged but rather make an application, and not be rejected by the lender ${ }^{10}$.

To focus ideas, an empirical model may encompass the following equations

$d_{i}^{d}=\beta^{\prime} x_{i}+\alpha_{i}+\varepsilon_{i} \quad$ the demand for debt

$l_{i}^{*}=\gamma_{1}^{\prime} z_{1 i}+\alpha_{1 i}+\varepsilon_{1 i} \quad$ positive debt selection equation

$a_{i}^{*}=\gamma_{2}^{\prime} z_{2 i}+\alpha_{2 i}+\varepsilon_{2 i} \quad$ application selection equation

$c_{i}^{*}=\gamma_{3}^{\prime} z_{3 i}+\alpha_{3 i}+\varepsilon_{3 i} \quad$ credit constraint selection equation

where $d_{i}^{d}$ denotes the demand for debt by household $i$, and $\mathrm{x}_{1 \mathrm{i}}$ is a vector of variables that explain demand by household $i$. The $\alpha_{i}$ are household-specific, time-invariant effects and capture factors like household-specific interest rates, marginal tax rates, preferences, lender's risk assessment of the applicant (rather than the application), and so on. Of course if we estimated the parameters of equation (6.1) using only those households of row 1 in the table and the error terms in the four equations were correlated, then sample selection biased would result.

\footnotetext{
${ }^{10}$ In all four data sets we observe the details on whether or not a household holds any debt (including the structure of debt portfolios), the amounts of debt outstanding, whether or not a household has applied for credit in the recent past, whether or not applications were turned down, and whether or not households refrained from applying in anticipation of rejection. However, both theoretical reasoning and the empirical structure sketched above are cast in terms of a particular credit contract with a given interest rate about which a decision is made at a particular point in time. Data questionnaires are typically not as precise and do not meet this conditioning. For the US and Netherlands a household may therefore be observed to be discouraged and yet apply, be rejected, and yet obtain a loan of desired size-possibly at a different interest rate or from a different lender or at a slightly different point in time.

In addition, credit applications may be understood as referring to a flow concept (addition to debt) rather than the stock of debt that we observe in the data. If we measured the flow by the change of the stock over time, our framework would still apply. Flows can, however, also be negative when repayments on the debt outstanding are made. In the Table, the difference between the last two lines is that the penultimate row only applies to the demand for a stock of debt whereas the last line relates to the demand for a flow of net credit extended. Other rows may equally apply to flow or stock concepts. In the case where the household wishes negative debt, only zero debt is observed.
} 
There are several possible ways to see the model and interpret what we observe in the data. For instance, if the model's equations are (6.1), (6.2) and (6.4) we might observe $d^{d}$ only if households hold positive debt and are unconstrained. The last equation allows, in principle, people to be rejected that have not applied, since the application decision is not separately modeled.

If the equations are (6.1) and (6.4) and the demand equation is modelled as a tobit (i.e., equation (6.2) is not separately specified), we assume the same process to determine the unconstrained zeros as the positive observations.

There are various other possibilities of tailoring the model to the data. In each case, interpretation of the parameter estimates will change. For instance, Duca and Rosenthal (1993), Cox and Jappelli (1993) and Crook (2001) estimate equations (6.1), (6.2) and (6.4) using cross sectional data only. Notice that whether a household desires positive debt or not will generally be correlated with whether the household applies or not since one might assume that many of those who desire debt will apply, unless transactions costs make application undesirable or a household believed it would be turned down.

\section{Empirical Results}

\subsection{Estimators and their Implementation}

The various models presented in the previous section may in principle be estimated on the available data. If we make distributional assumptions on both idiosyncratic errors and random effects, we can estimate the models by maximum likelihood (ML). ${ }^{11}$ However the derived ML estimators yielded implausible parameter estimates for Italy and the Netherlands, possibly indicating that one of the selection channels plays a minor role. This is consistent with the relatively few rejected or discouraged cases. In order to present estimates that can be meaningfully compared across countries, we therefore confine ourselves to single equation models. Here, we assume the household's utility from making an application depends on exogenous variables

\footnotetext{
11 This estimator has preferred asymptotic properties including efficiency, conditional on being correctly specified. The most convenient distributional assumption to make is that of multivariate normality, because this economises on the number of distributional parameters to be estimated while being entirely flexible as regards between-equation correlations. In addition, all marginals and conditional probabilities will be normal as well which is convenient for computational purposes.
}

For implementation, we chose to rely on gradient-based algorithms that require first analytical derivatives. Solving the problem proceeds iteratively. Starting values can be obtained from simplified models that obtain under parameter restrictions from the more general ones sketched above. Since the likelihood function requires multivariate integration, we considered maximizing a simulated likelihood function where the integral is replaced by a sum over simulated probabilities that obtain when the random effects are drawn from the distribution whose parameters we estimate along with the coefficients on the regressors.

During iterations it appeared that estimating these fairly general models with unrestricted betweenequation correlation structure of the composite errors is asking too much from both the Dutch and the Italian samples. Especially with the Italian data we found that between-equation correlations and variances would run off to the boundaries of the parameter space and eventually prevent the algorithm from finding a solution. In the Dutch case, we were able only to estimate a subset of the correlations, which however were not significantly different from zero. 
which the literature has suggested affect the desired volume of debt from the PIH. These variables are log current income, log difference between current and permanent income, age, and log net worth, and also taste shifters which may affect the parameters of a household's utility function: number of children of different ages, marital status, level of education, occupational status and gender. We have used the same variables for all four countries where possible. In addition, we control for time and regional effects without reporting them.

In addition, for the United States sample, as it is a repeated cross section, consistent two-step estimators for at least some of the selection models considered do exist. In this case we assume the model to consist of equations (6.1), (6.2) and (6.4) (excluding the random effects):

$$
\begin{array}{ll}
d_{i}^{d}=\beta^{\prime} x_{i}+\varepsilon_{i} & \text { the demand for debt } \\
l_{i}^{*}=\gamma_{1}^{\prime} z_{1 i}+\varepsilon_{1 i} & \text { positive debt selection equation } \\
c_{i}^{*}=\gamma_{3}^{\prime} z_{3 i}+\varepsilon_{3 i} & \text { credit constraint selection equation }
\end{array}
$$

We pooled those who were discouraged from applying together with those who were rejected since in this case also observed debt deviates from desired debt. So we have rows 1, 2 (combined with 3 ) and 4 in Table 7 with demand uniquely observed only for row 1. Notice that the errors of equations (7.2) and (7.3) may also be correlated. We followed the methodology of Tunali (1986) to estimate the parameters of this model (full details in Appendix 2) by OLS from the following second-stage equation:

$$
d_{i}^{d}=\beta^{\prime} x_{i}+\sigma_{\varepsilon_{i} \varepsilon_{1 i}} \lambda_{\varepsilon_{i} \varepsilon_{1 i}}+\sigma_{\varepsilon_{i} \varepsilon_{3 i}} \lambda_{\varepsilon_{i} \varepsilon_{3 i}}+\text { error }
$$

where $\lambda_{\varepsilon_{i} \varepsilon_{1 i}}$ and $\lambda_{\varepsilon_{i} \varepsilon_{3 i}}$ are the analogues of inverse Mill's ratios which are estimated from a first-stage bivariate probit with selection consisting of equations (7.2) and (7.3). Consistent standard errors for equation (7.4) were obtained by bootstrapping the estimates 1000 times. Since we are using the selection equations merely to remove sample selection bias in the parameters in equation (7.1), and since more variables are available for the US than for other countries, we can rely on a larger set of exclusion restrictions than would appear from the single-equation estimates that we present for the other countries.

\subsection{Credit Applications}

Table 8 shows the results for application decisions. Within the 1990s information on whether a household made an application is available only from 1995 onwards in both the US and Italy. Notice that the random effect for both the Netherlands and Italy contributes a statistically significant amount of variance to the overall variance. In all countries, greater net worth reduces the probability that a household will apply for any form of debt. However the marginal effect for Spain is three times that for the Netherlands which in turn is roughly double that for Italy and the US. The income patterns in all countries are difficult to characterize precisely, as we find the estimated spline function to change gradient, and sometimes direction in nonuniform ways. The overall impression is, however, that current income increases the probability of 
applying for loans in the European countries, whereas we see significantly negative impacts of income for the upper part of the income distribution in America.

\section{TABLE 8 HERE}

We control for the level of permanent income in these specifications by way of including the difference between current and permanent income. The reason for doing so is that demand for credit according to the PIH would be affected by changes in permanent income, once levels of incomes, wealth, and demographics are accounted for. There appears to be no effect for Italy, Spain or the United States. For the Netherlands, however, having current income exceed permanent income will decrease the probability of applying for new loans. On the background of the simple PIH story told above, this may be consistent with Dutch households interpreting a positive deviation from permanent income as a temporary income shock as its effect on consumption will be limited.

Age of the household head displays pronounced patterns in all four countries. To the extent that the marginal effect estimates are significant we observe a decreasing probability of applying with age. The age gradient increases (in absolute value) for both the US and Italy: as household heads become older they are increasingly less likely to apply for a loan. This result conforms with the intuition provided by the standard consumption models. We should add, though, that we have not controlled for cohort effects, which may lead the age coefficients to deviate from true life cycle profiles.

Neither in Italy, Spain nor in the Netherlands is there an effect of educational attainment on the probability of applying for credit. This is different in the US, where there is a greater probability that those who have a university degree or have gained vocational training will apply than the chance that those with merely primary or secondary school education. If education proxies income growth, we might expect such a pattern (although we do not control for time preference).

Family composition may matter because the presence and number of children, as well as their age may affect the marginal utility of consumption over the life cycle in predictable ways. We see that their importance differs across countries. Number of children at different ages tends to be important in Italy. Such effects are not observed for the other three countries. Part of this difference for the oldest age group, may be due to a slight difference in the question asked. In the US and the Netherlands the questionnaire asks whether the respondent or spouse applied whereas in Italy the questionnaire asks whether 'the household' applied and in Spain the subject could be either. ${ }^{12}$ So in Italy and possibly Spain the effect of older children applying for loans to finance their personal consumption may be counted towards a household credit application. A further significant difference is found for single person households who are less likely to apply than couples in any of the countries (not significant in Italy).

Clear differences are apparent in the effects of occupational status on the probability of applying. Compared with having a paid job, being unemployed reduces the

\footnotetext{
${ }^{12}$ The relevant question asks "How many loan applications have you made in the last two years (including applications to refinance previous loans)?" (p23) where "you" could be singular or plural.
} 
probability of application in the Netherlands and US, with a much larger marginal effect in the US than in the Netherlands. Unemployment has no effect in Italy but increases the chance of an application in Spain. For the US, having an occupation which does not give an income, being retired, or being disabled reduces the probability that a household will apply, compared to those with a paid job. In the European countries no other types of occupation have an effect on the probability of application.

Further, region and time effects are included but not reported in the table. In Italy there was a greater chance a household would apply in 1998 than in 1995, and a lower chance in 2002. In the US no differences between the years in the 1990s were detected. Finally the probability a household from the South or from the North East of Italy will apply is lower than the chance a household from the Central region will apply. With evidence from Fabbri and Padula (2004) that judicial costs are higher in the South of Italy than in the northern regions the lower application probability in the South may be due to banks requiring a higher deposit or charging a higher interest rate than institutions elsewhere in Italy. Obviously this would not explain the lower application rate in the North East. Regional effects are also detected in the Netherlands, although they do not lend themselves easily to interpretation. We cannot control for regional effects in the SCF or for Spain.

\subsection{Credit Constraints}

To investigate whether the characteristics of credit constrained households differ between countries and over time we again estimated random effects probits for the Netherlands and for Italy, a probit for Spain and pooled probits for the US. We used the same explanatory variables as before. Since all of these variables would also enter a credit scoring equation (Crook, Thomas and Hamilton 1992) the estimated parameters cannot be interpreted as those of a demand or of a supply equation, but merely as the difference in parameters between that in each of a demand and a supply equation.

We estimate three separate equations. In the first we model the probability that a household is rejected or gains only a part of their application, conditional on having applied. We have done this for all countries except Spain because the very small number of constrained households frustrated our attempts to gain plausible results. Second we consider all households and distinguish between (a) those who applied and were rejected or gained only part of the amount they applied for or those that did not apply and were discouraged from applying because they thought they would be turned down and (b) all others. Thirdly we consider all households and distinguish between (a) those who report that they have been rejected or unable to gain the entire amount they applied for or who report that they were discouraged from applying and (b) all others. Because of the questionnaire design the second and third definitions identify the same households as being constrained in Spain and also in Italy ${ }^{13}$ and so results for the third definition relate only to the Netherlands and US.

\footnotetext{
${ }^{13}$ In the Spanish EFF a household can be identified as discouraged only if it did not apply. The same applies in the Italian SHIW (after 1993).
} 
The first equation mirrors a stringent definition of being credit constrained in the sense that one can only be constrained if one actually applies for credit and is rejected. The second definition is somewhat laxer since it includes as constrained those who did not actually apply but who wished to have credit nevertheless and did not receive it. Such households may or may not have had an accurate expectation as to the reaction of a lender. But the point is that they did not gain all of the credit they wished to obtain. The third definition is consistent with the definition adopted by Cox and Jappelli (1993), Jappelli (1990), Crook (1996) and Crook (2001).

We argue that both definition 1 and 2 are a more reasonable interpretation of being credit constrained than certain others. For example, Duca and Rosenthal (1993) estimate the probability of being credit constrained using the above second definition applied only to a sample of debtors. But if a household's applications were all rejected this household would not appear in their sample of households who are credit constrained.

Tables $9 \mathrm{a}, \mathrm{b}$ and $\mathrm{c}$ show the estimated marginal effects at the means for the three definitions respectively. ${ }^{14}$ For the Italian data the random effect makes no contribution to the residual error of each equation and the same parameter values for each equation would result if the observations were all pooled over time.

Turning to the results for the first definition (Table 9a) we see that there is a lower probability that wealthier Dutch or American households would be rejected than lower-wealth households, but this was not found for Italian households. A negative effect is entirely expected: wealthier households have more collateral and may demand less debt, but the marginal effect is much greater for US households than for Dutch households.

\section{TABLES 9a-c HERE}

The effect of income also differs between the countries. In the Netherlands and Italy it has no separate effect whilst for American families the chance of rejection decreases for the third, fourth, and fifth quintile groups. This general effect is consistent with credit scoring models that find that increased income reduces the risk of default.

Perhaps one of the most important results is that the greater the amount by which income exceeds permanent income the greater the chance a household is credit constrained. This was found for three countries (although the Dutch coefficient is not significantly different from zero). This could be because the greater is income relative to permanent income the increase in a households demand for debt exceeds the increase in amount lenders are willing to supply. But we know from Table 8 that (except for the Netherlands) an increase in 'excess income' has no effect on the chance a household makes a credit application, so perhaps the effect is on the volume demanded by those who do apply. It seems highly unlikely that an increase in 'excess income' would increase the risk a lender may associate with an applicant, though it is possible when lenders believe that 'excess income' is indicative that future income will be lower than current income (mean reversion). However, there is no reported evidence in the literature that lenders behave in this way and much informal evidence

\footnotetext{
${ }^{14}$ Estimated coefficients and standard errors are available from the authors on request.
} 
that they do not. But if 'excess income' increases the demand for the volume of debt, this does not seem to be consistent with the PIH. Of course there are many interpretations of the term "permanent income" and our last statement can only be made for the interpretation implicit in the measure of permanent income that we have used. Our result would seem to be consistent with the "excess sensitivity" findings common in studies that use aggregate data.

The effect of age appears to differ between the three countries. In both the Netherlands and Italy, age of the household head does not appear to affect rejection significantly (pre-retirement Dutch households being the exception). In the US, increased age within one's 30s and over 65 years reduces the chance of being turned down. It is not immediately obvious why these differences between countries occur. On the supply side, credit scoring models for westernised countries generally find that age is negatively related to the chance of default (Crook, Thomas and Hamilton 1992). Indeed the Equal Credit opportunities Act 1974 in the US requires lenders to constrain risk assessment models which include age such that applicants over 62 years are regarded as of lower risk than younger applicants. So perhaps the age after which default risk falls differs between the countries. Perhaps this effect begins in the early 30 s in the US, whereas in Italy, where credit scoring models were introduced later than in the Netherlands or the US, age may not formally enter credit risk assessment procedures. On the demand side all combinations of parameters of the precautionary model predicted that the percentage of constrained households would decrease as age increases (Table 2). However other models of constraints might usefully be included in the model.

Education is only significant for the US again, where the estimation samples are also larger. Having completed high school or having gained a vocational qualification increases the chance of being rejected. The effects of the number of children differ between the countries. American and Italian households with more kids in the 7-12 years or 13-19 years age groups face a higher chance of being turned down and this extends to American families with kids ages 7-19 years but not to Italian households, and age of kids has no effect on the chance that a Dutch household would be turned down.

Turning to occupational status we again see some interesting differences. In the Netherlands, not having a job which provides income increases a household's chance of being turned down whereas in the US it actually reduces this probability and in Italy it has no effect. Disability appears to incur rejection in both US and Holland. In the US but not Italy or the Netherlands, being retired reduces the chance of being rejected. In the US but in neither European country being female reduces the chance of being constrained whereas in Italy, unlike the Netherlands or US, being single is disadvantageous. In the US single parents seem to have a higher chance of being turned down, but this was not found in the Netherlands or Italy.

Finally, regional differences (not reported in the Table) become apparent in the Netherlands but not in Italy. The absence of an effect for Italy means we should be cautious in concluding that higher judicial and enforcement costs in the South of Italy cause lenders to reject a higher proportion of credit applicants. 
When we include those families that were discouraged and did not apply into our definition of being credit constrained we gain essentially similar results (Table 9b), although the sample sizes increase substantially and we are able to compare with Spain. The differences in results compared with those in Table 9a for the US, Netherlands and Italy are as follows. When discouraged families are included, wealth becomes significantly negative for Italy, suggesting that the less wealthy are discouraged from making credit applications. This is also our conclusion for Spain and so for all four countries. Income is no longer significant for Italy and is not significant for Spain. The effect of a greater 'excess income' is positive and highly significant for Italy, the US and the Netherlands, but has no effect in Spain.

Including the discouraged would also alter our conclusions about the effect of age and education. The effect of age reducing the chance of being constrained is much more apparent with the effect occurring during one's 30s amongst Dutch and US households and in one's 40s amongst Italian families. Households with heads over 50 years in the US and over 65 years in Italy face further reduced chances of being constrained. Turning to education, the somewhat more highly educated (education class 6) are less likely to be discouraged (or rejected) in the Netherlands, and in Spain this is generally true for those that completed their education after primary level. For American families including the discouraged leads to the increased chance of being constrained to extend to those that completed their education after just primary level, a clear contrast with the effect for Spain. Again to interpret this result we need to know the effect of education on the volume of debt demanded.

Including the discouraged would also alter our conclusions on the effect of the number of children. The US and Dutch results remain the same. In Spain like in the Netherlands number of kids has no effect. But now on average an Italian family with more children in the age range 7 to 12 years or above 20 would face a greater chance of being constrained, just as in the US. As before, a difference in terms of questionnaire may contribute to the difference, especially for older children: Italian children tend to live with their parents until their thirties while trying to find independent housing and applying for mortgages. Asking if a member of the household had been discouraged from applying combined with the higher deposits required by mortgage grantors in Italy than elsewhere may disproportionately pick out families of those type of young would-be home owners.

Adopting the second definition of being credit constrained does not alter our findings on the effects of different occupations with the exception that a Dutch household is more likely to be credit constrained if its head is self-employed compared to being an employee. Italian and Spanish households are more likely to be constrained if the head is unemployed. Clearly being unemployed discourages Italian households from applying.

Regional differences do become important in Italy when the discouraged are included and they remain significant in the Netherlands. In Italy, we find that the average family living in the North West or South or the Islands has a lower chance of being constrained than one living in the Central region. This result appears to contradict the findings of Fabbri and Padula (2004) that higher judicial costs in the South increase the chance of being constrained. 
If we compare our results with the literature, the paper with the closest definition to our second definition is the one by Duca and Rosenthal (1993) using the 1983 SCF. They find none of the variables we have included to be significant. But their sample differs considerably from ours (apart from the time period). We include all households whereas they include only households where the head is aged under 35 years, with wealth no more than $\$ 1 \mathrm{~m}$ and who are not in the high income over sample. Moreover they estimate their model over households that have positive debt whereas we estimate our results from households who applied in the previous five years. Magri (2002) considered the 1989, 1995 and 1998 waves of the SHIW and found increased income and being self-employed increased the chance of being constrained whilst being married reduced the chance.

Our third definition of being constrained (Table 9c) identifies those households that were rejected or discouraged (regardless of whether they applied or not). Remember that households that did not say they fitted into either of these categories may have not wished to have any debt, whereas those who did reply affirmatively certainly did wish to have credit. Since we are not making the definition conditional on having applied or not applied for credit we can include an additional year (1992) in the US sample. Our findings here are very similar to those for the last definition (Table 9b), and we highlight some of the differences.

For the Dutch sample, we see now a significantly lower probability of being constrained when income increases for just below median households. Also, there are now stronger and significant negative impacts of age for both Holland and the US, with households in their 40s in the US now being more likely to be constrained. But the marginal effects remain considerably lower in the Netherlands than in the US.

In terms of labour market, self-employed are more likely to be constrained in both countries. American unemployed heads are less likely to be constrained, but unemployment has no effect in Holland. To interpret this, observe that in the SCF a household can be both discouraged and yet apply. For instance, it might apply to a place other than the place where it thought it would be turned down. So it possible that unemployed in the US were less discouraged than those in paid jobs because they were more likely to think of applying to sub-prime lenders of various types.

Other demographics do change in terms of impact for the US, where we now find a significant negative impact of being female and a positive one of being divorced or widowed.

Once again, recall that in this definition we populate the sample with potentially those that have no demand for credit, which perhaps mixes effects from the various equations that we delineated in the earlier section. The definition has been employed elsewhere, however, and we may shortly contrast these findings with ours. Cox and Jappelli (1993) use the 1983 SCF and Crook (2001) the 1995 SCF. The same results were obtained for wealth, family size, gender, and age.

\subsection{Household Debt: Amounts}

Since a household is credit constrained when its demand for debt exceeds its supply we cannot fully interpret the equations in the last section without having an 
understanding of intercountry differences in the determinants of the demand for debt. This is the aim of this section. As explained before, selection bias may not be much of an issue for the Netherlands and Italy, and we can explicitly check for the US. So we concentrate on regressing the (log of) the level of total debt held on regressors, conditional on holding positive debt for the Netherlands and Italy and on a sample selection corrected equation for the US where the selection of a sample with positive debt does appear to induce bias. We use a Tobit for Spain where a positive debt sample otherwise gives implausible parameters. In all cases we are interested in the marginal effects in the whole population, not merely those with positive debt.

Table 10 gives the results. Indeed, across the board signs and significance levels of coefficient estimates differ substantially from those in exercises conducted with the other equations, suggesting that different processes for application, rejection, and debt holding are at work.

\section{TABLE 10 HERE}

The effect of wealth on demand is strongly negative in the Netherlands and Italy with the marginal effects being similar. In the US the sample selection equation indicates that wealth has no effect. The same is true of Spain. This is consistent with the ranking of countries we would expect if bankruptcy protection impacted on the demand by high asset households, as studies for the United States suggest they do (Gropp, Scholz and White 1997).

Increased income in the second ntile group increases demand in all four countries but after that the effect differs noticeably between the countries. In the United States demand increases as household income increases within each income ntile. But in Italy increased income has no effect on demand unless the family is in the highest ntile group. Dutch households' demand shows plateau effects with income. As income increases within the second and third ntile groups demand increases, it then stays at that level throughout the fourth group, increases within the fifth group but does not increase thereafter. In addition the marginal effects for households in the United States, Holland and Spain are generally larger than the marginal effects for Italian families.

An interesting finding is that the greater the amount by which income is below permanent income the greater the amount of debt demanded in both the Netherlands and United States, but demand does not change in Italy or Spain. For the Netherlands and the United States this is consistent with the CE version of the PIH, though we have considered debt in aggregate rather than mortgage and consumer debt separately. Combining this result with our earlier results we now have a good picture of the households' decisions in four countries. Italy Spain and the United States are similar and differ from the Netherlands. In Italy and Spain, there is no effect on the chance that a household will apply for credit the lower is income below permanent income and there would be no effect either on the amount demanded by those who do apply. But in Holland the lower is income below permanent income the more likely a household will apply, the greater the amount the household will ask for. Interestingly this has no effect on the chance of being constrained. For American households a reduction in income below permanent income will not affect the chance it will apply for a loan but it will increase the amount demanded. It will also reduce the chance it is 
constrained. This is a puzzle that at present we are unable to resolve. One might expect that a household with an income much below permanent income would have a lower chance of being offered debt rather than a higher chance compared to a family with higher income relative to permanent income. Indeed credit scoring models typically include income as a predictive variable though its contribution is usually relatively small..

The effect of age on demand is consistent with the CE version of the PIH for the Netherlands, Spain and the United States, but slightly less so for Italy. In the Netherlands demand increases until age 40, and 30ish in the United States. In Spain demand decreases progressively as the head of the household becomes older than 30 years, in the Netherlands demand decreases progressively as the head of household becomes older than 50 years whilst in the United States the decrease in demand only starts from age 65. Surprisingly, in Italy demand decreases as the head ages between 40 and 65 years whereafter it stays constant.

These findings are also consistent with the precautionary consumption model (Table 2) for the Netherlands and the United States. The benchmark case shows mean debt divided by income ratios, both conditional and unconditional, increasing to age 40 and declining thereafter. The ratio plummets after age 50 but patterns which are more consistent with the data for the Netherlands and the United States can be seen if the income shocks are reduced or the time preference rate increased above the benchmark figures. The observed constant demand after age 65 for Italy is not predicted by the precautionary model unless the parameters are set to result in no debt being held. The decreased demand after age 30 is predicted if retirement income as a proportion of pre-retirement income is lowered to $65 \%$, or if income growth is considerably increased.

The effect of education also differs between the three countries. Having earned a high school diploma or university degree rather than merely leaving after elementary school increases demand in Italy. In the United States having completed high school actual reduces demand whilst other educational levels completed have no different effect compared with elementary school. In the Netherlands having had a vocational training or a university degree increases demand relative to merely leaving after primary school. In Spain education has no effect. More young children under the age of 6 years increase the amount of debt demanded in the Netherlands, Spain and the United States but do not alter demand in Italy. Having more pre-teenage kids increases demand in Spain and the United States, but not elsewhere. Interestingly, having more teenage kids in the family in the United States increases demand, but does not do so in the other countries.

Being unemployed appears to have no effect on the desired stock of debt, except for the Netherlands. If debt is providing insurance against unexpected income shocks one would expect those who are unemployed to desire more debt to smooth consumption. But if a household expects a spell of unemployment to be long-term it would not desire more debt. Our result is consistent with the latter hypothesis but does not seem to be consistent with the former. Of course the effect may be on the flow of credit rather than the stock of debt. 
Various other employment states also have no effect on demand: having an occupation which yields no income (no paid job), being retired (except in Spain), having another job or being disabled. In Italy, Holland and the United States the self employed demand considerably more debt than others, but not in Spain. The absence of an effect in Spain is surprising because it has the highest employment protection. The greater effect of being self employed in Italy than in the United States is slightly puzzling because bankruptcy protection appears greater in the US than in Italy. But it may reflect differences in the structure of the debt markets between the countries with small business loans being less available from financial institutions in Italy than in the United States. ${ }^{15}$

Female heads of households demand less debt in the Netherlands and in the United States though for the United States the effect is only detectable for the population as a whole and not for those who have debt. Gender has no effect in Italy or Spain. Single people demand less debt in the Netherlands, Italy and Spain which is unsurprising, but not in the United States, although those who are divorced or widowed demand less only in the Netherlands and Spain. Single parents demand less in the Netherlands but not in Italy, Spain or the United States. This may reflect the greater provision of welfare funding in the Netherlands than in the other two countries.

Finally, some comments on the selection model discussed at the end of section 6 are in order. The debt holding equation (7.1) is corrected for bivariate selectivity from those that are unconstrained conditional on having positive debt. In this definition, we include the discouraged ones with the constrained ones and estimate the selection process on the full sample. We identify the effect nonparametrically by imposing exclusion restrictions. We include in the constrained equation, but exclude from the positive debt equation, whether the household had been two or more months behind with credit payments in the last six months (Default), whether the head or spouse was currently social security benefit payments (Welfare), number of years the head has worked for the same employer (Years at job) and number of financial institutions the family has accounts or loans with (No of accounts). These variables are the type that appear in credit scoring models and are less likely to affect whether a household desires debt than whether the household is likely to be rejected by a lender. Equation 7.3 was identified by including attitudes towards the use of credit for the purchase of certain items (fur coats, cars, vacations, education and living expenses when income is cut), which would not be observed by financial institutions in the positive debt equation, but excluding them from the constrained equation. The demand for debt equation (7.1) is then identified by the combined exclusion restrictions (and, differences in functional form in the age and income regressors). The estimated parameters of the selection equations for the US are given in Appendix 3. This shows that most of the identifying variables are significant, in some cases very highly so, with the expected sign.

We find evidence of selection bias for the US if we had only sampled those with debt. Formally, the selection correction term for having positive debt is significant, but notice that the one for not being constrained is not significant (this conclusion is based on bootstrapped standard errors). Quantitatively, in almost all cases except for wealth,

\footnotetext{
${ }^{15}$ Remember that the stock of debt for Italy excludes debt supplied by relatives and friends, unlike the US and NL data.
} 
we observe only minor differences between coefficient estimates between the selection-corrected estimates and the pooled-OLS case (final column in Table 10).

\section{Conclusions}

In this paper we have investigated the prevalence of household debt holding and the incidence of being credit constrained using comparable micro data from four OECD countries: the United States, the Netherlands, Italy and Spain. We measure credit constraints from self-reports on having been turned down for a credit application, but can also take into account discouraged would-be applicants.

We document stark differences across these countries in terms of debt incidence, debt levels, and the proportion of rationed households (whose demand is not met at the given interest rate). We generate quantitative predictions from a simulated life cycle precautionary savings model to understand how parameters of a consumer's problem influence demand for credit and severity of binding constraints. Whilst many of these parameters are not directly observable, we can ascribe differences in credit market behaviour to differences in household characteristics.

In summary, we find that a much greater proportion of US households apply for credit than for the Netherlands or Spain with Italy far behind. This is due to a combination of factors. Whilst Americans have much higher wealth than households in Italy, Spain or the Netherlands, this only acts to reduce the chance of application and so is outweighed by the effect of higher American incomes. Income further below permanent income increases the chance of application amongst Dutch families which is consistent with the certainty equivalence version of the permanent income hypothesis. However, contrary to the hypothesis, income has no effect amongst US, Spanish or Italian families. The average age of US heads of households is comparable to that in Italy, Spain and the Netherlands but the marginal effects of age, especially above 50 years, acts to reduce the chance a family applies. Being unemployed reduces the chance of application, in the US and in Holland, suggesting unemployment is either not expected to be temporary there or that credit is not being used to smooth consumption. Single household heads also have a lower chance of applying.

Of those households who do apply a much higher proportion are rejected in the US than in either the Netherlands or Italy and especially Spain. Including those households that are discouraged from applying suggests that a considerably smaller percentage of Italian, Spanish and Dutch households are credit constrained than of American families. In fact, the proportion of Dutch, Spanish and Italian households who actually declare themselves to be constrained is tiny in comparison with the percentage for the US. Again, wealth acts to reduce the chance of being constrained in all four countries with a relatively large marginal effect in the US. Age reduces the chance of being constrained with each year having a greater effect on the chance of being constrained in the US than in Italy or the Netherlands. But age has no effect in Spain. Being retired reduces the chance a household is constrained in the US, whereas in both the US and Netherlands having a disability increases the chance. Being unemployed increases the chance of being turned down or discouraged from applying in Italy and the United States. 
Finally, average debt holdings are ten times higher in the US than in Italy, five times higher than in Spain with the Netherlands around three quarters that of the US. More wealthy households demand less debt in Italy and the Netherlands, but wealth has no effect in Spain or in the US, apart from within the group that possesses debt. We are unable to explain why income further below permanent income increases the demand for debt but reduces the chance that a household is constrained. Demand follows the $\mathrm{CE}$ and precautionary savings versions of the PIH with respect to age and whilst the effect of total income is monotonically positive in the US there are plateau effects in Italy, Spain and the Netherlands. Having teenage kids increases demand in the US, but surprisingly has no effect in Italy, Spain or the Netherlands. Apart from the selfemployed demanding more debt in the US and Italy, labour market variables have no discernable effect.

Many of the unexplained observed inter-country differences are however likely due to institutional differences between the four countries. Employment protection is greater in Italy, Spain and the Netherlands than in the US, and income uncertainty is highest in the US than in the Netherlands or Italy. So we would expect less willingness to borrow, because of greater repayment uncertainty, in the US than in Italy, Spain and the Netherlands. In the US there is more protection in the event of bankruptcy than in the Netherlands or Italy suggesting greater supply and also greater demand by wealthier households in the former than in the latter countries. Collateral liquidation costs are much higher in Italy than in the other countries and there is a lower degree of information sharing via credit bureaus in Italy, suggesting greater information asymmetry between lenders and borrowers. Homeownership rates are highest in Spain and Italy followed by the US and finally the Netherlands with house prices increasing rapidly in the Netherlands, Spain and the US, but less rapidly in Italy. Mortgage demand should therefore be greater in Italy, Spain and the Netherlands than in the US. On the other hand, down payment ratios are higher in Italy than in the Netherlands, Spain and the US so reducing mortgage demand in Italy, and this is exasperated by the higher prepayment penalties in Italy than in the Netherlands and the US. Mortgage payments are fully tax deductible in the Netherlands, but only up to a limit in the US and especially in Italy, reducing net interest rates in the Netherlands compared with the US and Italy respectively. 


\section{References}

Aizcorbe, Ana M., Arthur B. Kennickell, and Kevin B. Moore (2003): "Recent Changes in U.S. Family Finances: Evidence from the 1998 and 2001 Survey of Consumer Finances", Federal Reserve Bulletin, January 2003, 1-32.

Alessie, Rob, Stefan Hochguertel and Arthur van Soest (2002): "Household Portfolios in the Netherlands," chapter 9 in Guiso, Haliassos and Jappelli (eds.) (2002).

Alessie, Rob, Stefan Hochguertel and Guglielmo Weber (2005): "Consumer Credit: Evidence from Italian Micro Data," Journal of the European Economic Association, 3, 144-178.

Allen, Franklin, Michael K. F. Chui, and Angela Maddaloni (2004): "Financial Systems in Europe, the USA, and ASIA," Oxford Review of Economic Policy, 20, 490-508.

Bacchetta, Philippe and Stefan Gerlach (1997): "Consumption and Credit Constraints: International Evidence," Journal of Monetary Economics, 40, 207-238.

Banks, James, Richard Blundell and James P. Smith (2003): "Understanding the Differences in Household Financial Wealth between the United States and Great Britain," Journal of Human Resources, 38, 241-279.

Baxter, W F (1995): "Section 85 of the National Bank Act and consumer welfare," Utah Law Review.

Berkowitz, Jeremy, and Richard Hynes (1999): "Bankruptcy Exemptions and the Market for Mortgage Loans," Journal of Law and Economics, 42, 908-830.

Bertaut, Carol, and Martha Starr-McCluer (2002): "Household Portfolios in the United States," in Guiso, Haliassos and Jappelli (eds.) (2002).

Bertola, Giuseppe, Richard Disney, and Charles Grant, eds. (2006 forthcoming): The Economics of Consumer Credit. Cambridge MA: MIT Press.

Bertola, Giuseppe, and Richard Rogerson (1997): "Institutions and Labor Reallocation," European Economic Review, 41, 1147-1171.

Bianco, Magda, Tullio Jappelli, and Marco Pagano (2005): "Courts and Banks: Effects of Judicial Enforcement on Credit Markets," Journal of Money, Banking, and Finance, (forthcoming).

Börsch-Supan, Axel and Anna Maria Lusardi (2003): "Saving: A Cross-National Perspective," in A. Börsch-Supan (ed.), Life-Cycle Savings and Public Policy: A Cross-National Study in Six Countries, Academic Press, 1-31.

Bover, Olympia (2004): "The Spanish Survey of Household Finances (EFF): Description and Methods of the 2002 Wave," Documentos Ocasionales No. 0409, Banco de Espana, Madrid.

Brandolini, Andrea, and Luigi Cannari (1994): "Methodological Appendix: The Bank of Italy's Survey of Household Income and Wealth," in A. Ando, L. Guiso, and I. Visco (eds.) Saving and the Accumulation of Wealth: Essays on Italian Household and Government Behaviour. Cambridge: Cambridge University Press. 
Canner, Glenn B. and James T. Fergus (1987): "The effects on consumers and creditors of proposed ceilings on credit card interest rates," Staff Studies Paper 154, Wshington DC: Board of Governors of the Federal Reserve System.

Carroll, Christoper D. (1997): "Buffer-stock Saving and the Life-cylce/Permanent Income Hypothesis," Quarterly Journal of Economics, 112, 1-55.

Chiuri, Maria-Concetta and Tullio Jappelli (2003): "Financial Market Imperfection and Home Ownership: A Comparative Study," European Economic Review, 47, 857-875.

Cox, Donald and Tullio Jappelli (1993): "The Effect of Borrowing Constraints on Consumer Liabilities," Journal of Money, Credit and Banking, 25, 197-213.

Crook, Jonathan N., Lyn C. Thomas and Robert Hamilton (1992): "The degradation of the scorecard over the business cycle," IMA Journal of Mathematics Applied in Business and Industry, 4(1), 111-123..

Crook, Jonathan N. (1996) Credit constraints and US households, Applied Financial Economics, 6, 477-485.

Crook, Jonathan (2001): "The demand for household debt in the USA: evidence from the 1995 Survey of Consumer Finance," Applied Financial Economics, 11, 8391.

Crook, Jonathan (2006a): "The demand and supply of household debt: a cross country Comparison," Chapter 3 in Bertola, Disney, and Grant, (eds.) (2006).

Crook, Jonathan (2005): "The Measurement of Household Liabilities: Conceptual Issues and Practice". Credit Research Centre, University of Edinburgh, Working Paper 01/05.

Das, Marcel, and Bas Donkers (1999): "How Certain Are Dutch Households About Future Income: An Empirical Analysis?" Review of Income and Wealth, 45, 325-338.

Deaton, Angus (1991): "Saving and Liquidity Constraints," Econometrica, 59, 12211248.

Deaton, Angus (1992): Understanding Consumption Oxford: Oxford University Press.

Djankov, Simeon, Rafael La Porta, Florencio Lopez-de-Silanes, and Andrei Shleifer (2003), "Courts," Quarterly Journal of Economics, 118, 453-517.

Duca, John V. and Stuart S. Rosenthal (1993): "Borrowing Constraints, Household Debt and Racial Discrimination in the Loan Market," Journal of Financial Intermediation, 3, 77-103.

Engen, Eric M., and Willam G. Gale (1996): "Tax-Preferred Assets and Debt, and the Tax Reform Act of 1986: Some Implications for Fundamental Tax Reform," National Tax Journal, 49, 331-339.

European Commision (2004). The Social Situation of the European Union, 2004. Brussels.

Fabbri, Daniele and Mario Padula (2004): "Does poor legal enforcement make households credit constrained?" Journal of Banking and Finance, 28(10), 2369-2397. 
Ferri, G. and Simon, P. (2002): "Constrained consumer lending: methods using the Survey of Consumer Finances," University of Bari, working paper.

Glaeser, Edward L. and Jose A. Scheinkman (1998): "Neither a Borrower nor a Lender Be: An Economic Analysis of Interest Restrictions and Usury Laws," Journal of Law and Economics, 41, 1-36.

Gropp, Reint, and John Karl Scholz, and Michelle J. White (1997): "Personal Bankruptcy and Credit Supply and Demand," Quarterly Journal of Economics, 112, 217-251.

Guiso, Luigi, Tullio Jappelli and David Terlizzese (1994): "Why is Italy's saving rate so high?" in Albert Ando, Luigi Guiso and Ignazio Visco (eds) Savings and the Accumulation of Wealth. Essays on Italian Households and Government Saving Behaviour. Cambridge: Cambridge University Press.

Guiso, Luigi, Tullio Jappelli, and Luigi Pistaferri (2002): “An Empirical Analysis of Earnings and Employment Risk," Journal of Business and Economic Statistics, 20, 241-253.

Guiso, Luigi, Michael Haliassos, and Tullio Jappelli (eds.) (2002): Household Portfolios. Cambridge, MA: MIT Press.

Guiso, Luigi, and Tullio Jappelli (2002): "Household Portfolios in Italy," Chapter 7 in Guiso, Haliassos and Jappelli (eds.) (2002).

Hayashi, Fumio (1987): "Tests for liquidity constraints: a critical survey and some new observations," in Bewley, T.F. (ed), Advances in Econometrics: Fifth World Congress, vol. II, 91-120.

Hurd, Michael, and Arie Kapteyn (2003): "Health, Wealth, and the Role of Institutions," Journal of Human Resources, 38, 386-415.

Jappelli, T. (1990): "Who is credit constrained in the US economy," Quarterly Journal of Economics, 105, 219-234.

Jappelli, Tullio, and Marco Pagano (1989): "Aggregate Consumption and Capital Market Imperfections: An International Comparison," American Economic Review, 79, 1088-1105.

Jappelli, Tullio, and Marco Pagano (2002): "Information Sharing, Lending, and Defaults: Cross-country Evidence," Journal of Banking and Finance, 26, 2017-2045.

Jappelli, Tullio, and Luigi Pistaferri (2004): "Incentives To Borrow And The Demand For Mortgage Debt: An Analysis Of Tax Reforms," CEPR Discussion Paper 2903..

Kapteyn, Arie and Constantijn Panis (2003): "The Size and Composition of Wealth Holdings in the United States, Italy, and the Netherlands," NBER Working Paper, \#10182.

Kapteyn, Arie, Rob Alessie, and Annamaria Lusardi (2005): "Explaining the Wealth Holdings of Different Cohorts: Productivity Growth and Social Security," European Economic Review, 49, 1361-3191.

King, Mervin, and Louis Dicks-Mireaux (1982): "Asset Holdings and the LifeCycle," Economic Journal, 92, 247-267. 
La Cava, Gianni and John Simon (2003) "A tale of two surveys: household debt and financial constraints in Australia", Research Discussion Paper, Reserve Bank of Australia.

Lin, Emily Y., and Michelle J. White (2001): "Bankruptcy and the Market for Mortgage and Home Improvement Loans," Journal of Urban Economics, 50, 138-162.

Low, Simon, Matthew Sebag-Montefiore, and Achim Dübel (2003): "Study on the Financial Integration of European Mortgage Markets," European Mortgage Foundation and Mercer Oliver Wyman.

Lyons, Angela C (2003): "How Credit Access Has Changed Over Time For US Households," Journal of Consumer Affairs, 37(2), 231-255 .

Magri, Silvia (2002): "Italian Household Debt: Determinants of Demand and Supply," Banca d'Italia, Temi di discussione del Servizio Studi, no. 454.

Maki, Dean M. (2001): "Household Debt and the Tax Reform Act of 1986," American Economic Review, 91, 305-319.

Mariger, Randall P. (1987) A life-cycle consumption model with liquidity constraints: theory with empirical results. Econometrica, 55, 533-557.

OECD (1999): Classifying Education Programmes. Manual for ISCED-97 Implementation in OECD Countries. Paris: Organization for Economic Cooperation and Development.

OECD (2000): "House prices and economic activity" Economic Outlook, No 68, December, 169-184, Paris. Organization for Economic Cooperation and Development.

OECD (2004): "Housing Markets, Wealth and the Business Cycle," Economic Outlook, No. 75, June, 5-28, Paris. Organization for Economic Cooperation and Development.

Stiglitz, Joseph E., and Andrew A. Weiss (1981): "Credit Rationing in Markets with Imperfect Information,” American Economic Review, 71, 393-410.

Tunali , I. (1986) "A General Structure For Models Of Double-Selection And An Application To A Joint Migration/Earnings Process With Remigration", Research in Labor Economics, 8(b), 235-282.

Villegas, Daniel J. (1989): "The Impact of Usury Ceilings on Consumer Credit," Southern Economic Journal, 56, 126-141.

Welan, Gary (2000) : "Interstate Banking, Branching, Organisation Size, and Market Rivalry," Economic and Policy Analysis Working Paper 2000-7, Washington DC: Office of the Comptroller of the Currency..

White, Michelle J. (2006): "Bankruptcy and Consumer Behavior: Theory and US Evidence," Chapter 7 in Bertola, Disney, and Grant, (eds.) (2006).

Zeldes, Stephen P. (1989): "Consumption and Liquidity Constraints: An Empirical Investigation," Journal of Political Economy, 97, 305-346. 


\section{Data Appendix}

\section{Age (for all countries)}

The interpretation of the coefficients in each equation of the form $y_{i}=\beta_{k i}^{\prime} x_{k i}+\sum_{q} \beta_{q} a g e_{i}+\varepsilon_{i}$ where q denotes spline $\mathrm{q}$, is:

$\begin{array}{lll}d y & \beta_{1} & \text { if age }<30 \\ \text { dage } & \beta_{2} & \text { if } 30 \leq \text { age }<40 \\ & \beta_{3} & \text { if } 40 \leq \text { age }<50 \\ & \beta_{4} & \text { if } 50 \leq \text { age }<650 \\ & \beta_{5} & \text { if } 65 \leq \text { age }\end{array}$

Education

Education variables standardised on OECD (1999). The classification refers to educational stages completed, rather than merely being undertaken.

Variable Description

Classification
ISCED97

0,1

$2 \mathrm{~A}, \mathrm{~B}, \mathrm{C}$

$3 \mathrm{~A}, \mathrm{~B}, \mathrm{C}$

$4 \mathrm{~A}, \mathrm{~B}, \mathrm{C}$

5 A, B, 6 


\section{Appendix 2}

\section{Details of the Parameter Estimation for the Demand Function for the US}

The method for estimation is a two stage procedure originally proposed by Heckman (1976) and follows Tunali (1986) who specifically derives the likelihood function in the case of two selection equations with partial observability.

The model consists of three equations:

$d_{i}^{d}=\beta^{\prime} x_{i}+\varepsilon_{i} \quad$ the demand for debt

$l_{i}^{*}=\gamma_{1}^{\prime} z_{1 i}+\varepsilon_{1 i} \quad$ positive debt selection equation

$c_{i}^{*}=\gamma_{3}^{\prime} z_{3 i}+\varepsilon_{3 i} \quad$ credit constraint selection equation

We observe the amount of debt demanded only when when $l_{i}=c_{i}=1$.

We assume that $\varepsilon_{1 i}, \varepsilon_{2 i}$, and $\varepsilon_{3 i}$ are distributed trivariate normal with zero mean and

covariance matrix: $\left(\begin{array}{lll}\sigma^{2} & \sigma_{i, \varepsilon_{1 i}} & \sigma_{i, \varepsilon_{3 i}} \\ \sigma_{i, \varepsilon_{1 i}} & 1 & \sigma_{\varepsilon_{1 i}, \varepsilon_{3 i}} \\ \sigma_{i, \varepsilon_{3 i}} & \sigma_{\varepsilon_{1}, \varepsilon_{3}} & 1\end{array}\right)$

The conditional expectation of equation (A2.1) conditional on selection is:

$$
\begin{aligned}
& E\left(d_{i}^{d} \mid x_{1 i}, z_{1 i}, z_{3 i}, l_{i}, c_{i}\right)=\beta^{\prime} x_{i}+E\left(\varepsilon_{i} \mid \varepsilon_{1 i}>-\gamma_{1}^{\prime} z_{1 i}, \varepsilon_{3 i}>-\gamma_{3}^{\prime} z_{3 i}\right) \\
& =\beta^{\prime} x_{i}+\sigma_{\varepsilon_{i} \varepsilon_{1 i}} \lambda_{\varepsilon_{i} \varepsilon_{1 i}}+\sigma_{\varepsilon_{i} \varepsilon_{3 i}} \lambda_{\varepsilon_{i} \varepsilon_{3 i}}
\end{aligned}
$$

where

$$
\begin{aligned}
& \lambda_{\varepsilon_{i} \varepsilon_{1 i}}=\frac{\phi\left(\gamma_{1}^{\prime} z_{1 i}\right)\left[\Phi\left(\gamma_{3}^{\prime} z_{3 i}\right)-\rho\left(\gamma_{1}^{\prime} z_{1 i}\right)\right] /\left(1-\rho^{2}\right)^{1 / 2}}{G\left(\gamma_{1}^{\prime} z_{1 i}, \gamma_{3}^{\prime} z_{3 i} ; \rho\right)} \\
& \lambda_{\varepsilon_{i} \varepsilon_{3 i}}=\frac{\phi\left(\gamma_{3}^{\prime} z_{3 i}\right)\left[\Phi\left(\gamma_{1}^{\prime} z_{1 i}\right)-\rho\left(\gamma_{3}^{\prime} z_{3 i}\right)\right] /\left(1-\rho^{2}\right)^{1 / 2}}{G\left(\gamma_{3}^{\prime} z_{3 i}, \gamma_{1}^{\prime} z_{1 i} ; \rho\right)}
\end{aligned}
$$

where $\phi$ is the standard univariate normal density, $\Phi$ is the standard univariate cumulative distribution, $\mathrm{G}$ is the standard bivariate normal cumulative distribution and $\rho$ is the bivariate correlation coefficient between $\varepsilon_{1 \mathrm{i}}$ and $\varepsilon_{3 \mathrm{i}}$.

Equations A2.1 and A2.2 form a bivariate probit with selection model, the likelihood function for which is:

$$
L L_{i}=\ln \sum_{l_{i}=0}\left(1-\Phi\left(\gamma_{1} z_{1 i}\right)\right)+\ln \sum_{l_{i}=1, c_{i}=1}\left(G\left(\gamma_{1} z_{1 i},-\gamma_{3} z_{3 i},-\rho\right)\right)+\ln \sum_{l_{i}=1, c_{i}=0}\left(G\left(\gamma_{1} z_{1 i}, \gamma_{3} z_{3 i}, \rho\right)\right)
$$


Maximisation of A2.7 gives consistent estimates of $\gamma_{1}, \gamma_{3}$, and $\rho$. These can be inserted into A2.5 and A2.6 to give $\lambda_{\varepsilon_{i} \varepsilon_{1 i}}$ and $\lambda_{\varepsilon_{i} \varepsilon_{3 i}}$. These lambda values can then be inserted into the A2.4 to derive the regression equation for A2.1:

$d_{i}^{d}=\beta^{\prime} x_{i}+\sigma_{\varepsilon_{i} \varepsilon_{i i}} \lambda_{\varepsilon_{i} \varepsilon_{i i}}+\sigma_{\varepsilon_{i} \varepsilon_{3 i}} \lambda_{\varepsilon_{i} \varepsilon_{3 i}}$

which can be consistently estimated using OLS.

The usual estimates of the standard errors will be inconsistent. We estimate the standard errors by bootstrapping the estimates 1000 times. That is, samples of size equal to the entire sample, were randomly selected with replacement . For each such replication the parameters of equation A2.8 were estimated and the standard deviation of these estimates for each parameter computed. This standard deviation is taken to be the standard error of the original estimate of the parameter. 


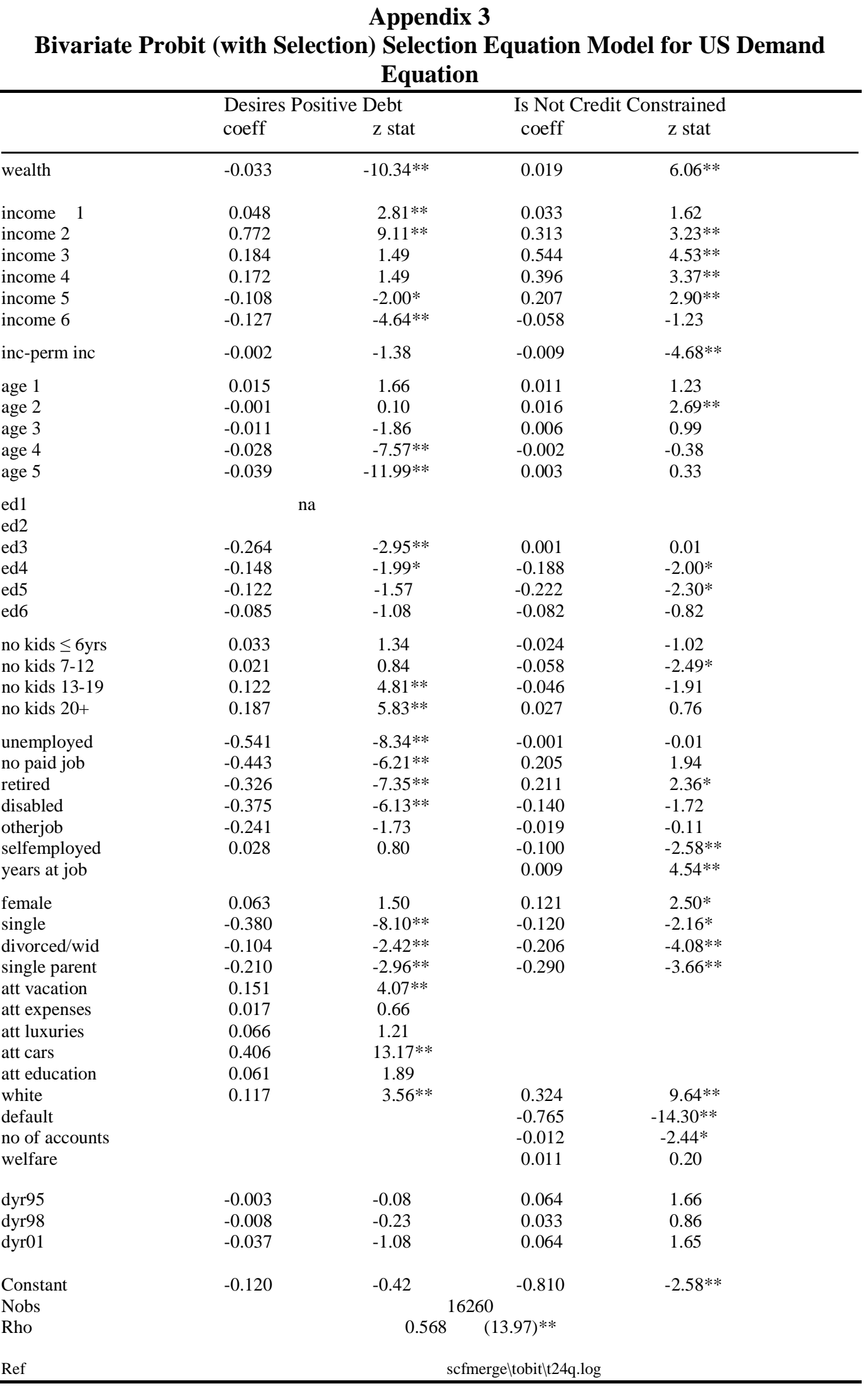

Notes: The LR test of Rho is distributed Chi squared (1). Number of uncensored observations (cases with debt $\leq 0$ ) is 12218 . Money values in 1992 Euros. * denotes significance at 5\%, ** denotes significance at $1 \%$. Income, wealth and (income permanent income) are $\ln (x+1)$ if $x \geq 0,-\ln (-x+1)$ if $x<0$. 
Figure 1

Stylized Certainty Equivalent Models with non-zero

Borrowing Constraint

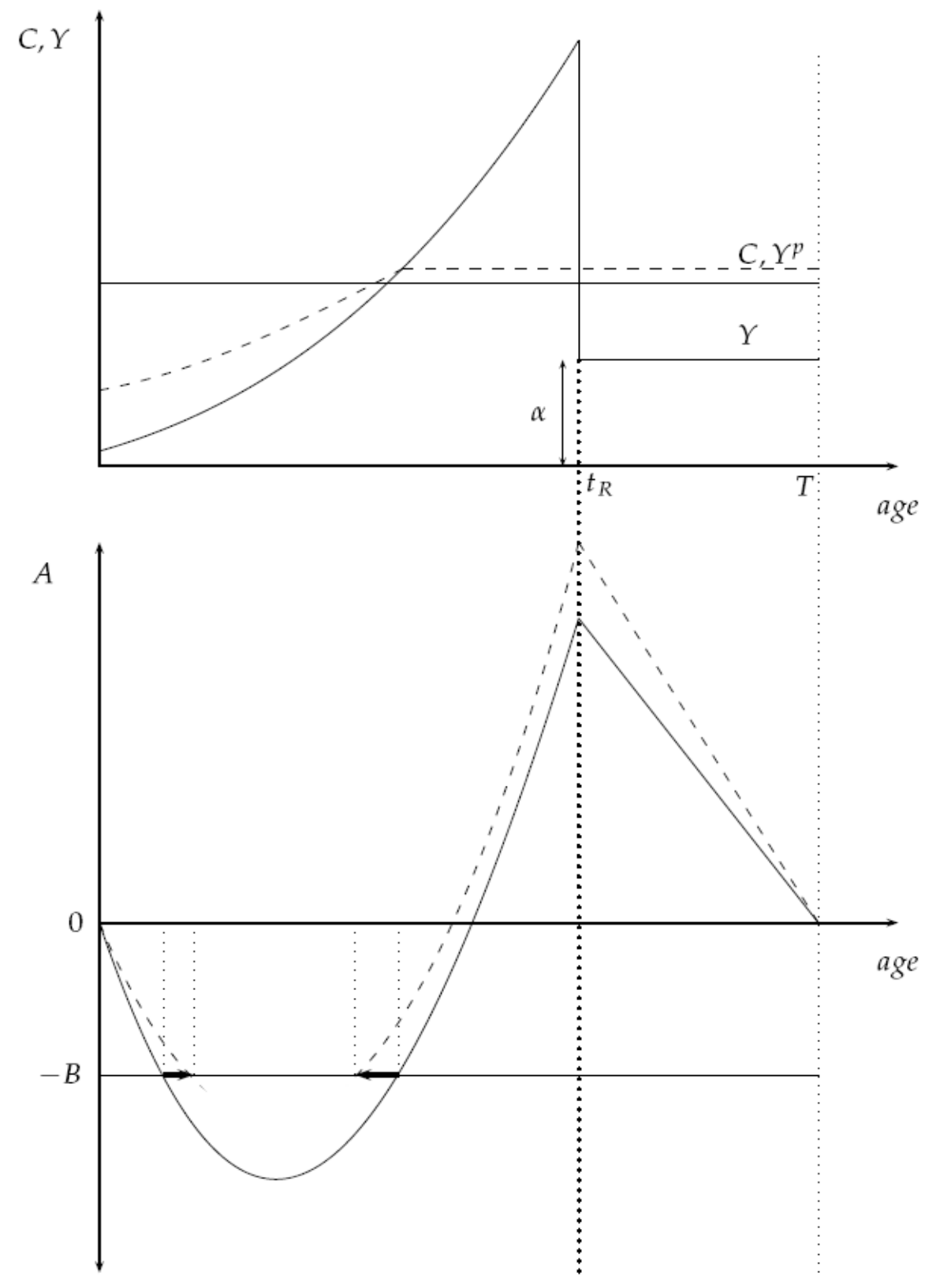


Table 1

Precautionary Model, Benchmark Parameters

\begin{tabular}{lll}
\hline Parameter & Value & Description \\
\hline$s$ & 25 & age of start of economic life \\
$t_{R}$ & 65 & retirement age \\
$T$ & 85 & terminal period \\
$\gamma$ & 2 & relative risk aversion \\
$\delta$ & 0.02 & time preference rate \\
$R$ & 1.02 & return on assets \\
$G$ & 1.02 & income growth \\
$\alpha$ & 0.75 & replacement rate \\
$Y^{p}{ }_{0}$ & 20 & initial value permanent income \\
$A_{0}$ & 0 & initial asset level \\
$B$ & 0 & borrowing constraint, if imposed \\
$\sigma_{\eta}$ & 0.10 & permanent shock \\
$\sigma_{\epsilon}$ & 0.10 & transitory shock \\
$N$ & 1000 & number of sample paths \\
\hline
\end{tabular}


Table 2

Precautionary Model: Simulation Results

\begin{tabular}{|c|c|c|c|c|c|c|}
\hline & & \multicolumn{5}{|c|}{ Benchmark (Table 1) } \\
\hline & age & 30 & 40 & 50 & 60 & 70 \\
\hline holds any debt & $\%$ & 81.1 & 73.4 & 23.3 & 0.2 & 0.0 \\
\hline constrained & $\%$ & 17.6 & 2.5 & 0.0 & 0.0 & 0.0 \\
\hline avg. debt/avg. income & & 0.197 & 0.235 & 0.041 & 0.000 & 0.000 \\
\hline indiv. debt/income & mean & 0.207 & 0.267 & 0.058 & 0.001 & 0.000 \\
\hline (unconditional) & median & 0.183 & 0.200 & 0.000 & 0.000 & 0.000 \\
\hline stddv & & 0.183 & 0.281 & 0.152 & 0.014 & 0.000 \\
\hline debt/income & mean & 0.256 & 0.364 & 0.247 & 0.312 & 0.000 \\
\hline (if debt >0) & median & 0.233 & 0.312 & 0.185 & 0.312 & 0.000 \\
\hline stddv & & 0.170 & 0.269 & 0.230 & 0.018 & 0.000 \\
\hline
\end{tabular}

\begin{tabular}{|c|c|c|c|c|c|c|c|c|c|c|c|}
\hline \multirow[b]{3}{*}{ holds any debt } & \multicolumn{6}{|c|}{ Benchmark, but $\alpha=0.65$} & \multicolumn{5}{|c|}{ Benchmark, but $G=1.015$} \\
\hline & age & 30 & 40 & 50 & 60 & 70 & 30 & 40 & 50 & 60 & 70 \\
\hline & $\%$ & 65.5 & 37.2 & 1.6 & 0.0 & 0.0 & 11.5 & 1.0 & 0.0 & 0.0 & 0.0 \\
\hline constrained & $\%$ & 13.6 & 0.1 & 0.0 & 0.0 & 0.0 & 3.9 & 0.0 & 0.0 & 0.0 & 0.0 \\
\hline avg. debt/avg. income & & 0.125 & 0.072 & 0.001 & 0.000 & 0.000 & 0.011 & 0.001 & 0.000 & 0.000 & 0.000 \\
\hline indiv. debt/income & mean & 0.133 & 0.085 & 0.002 & 0.000 & 0.000 & 0.012 & 0.001 & 0.000 & 0.000 & 0.000 \\
\hline (unconditional) & median & 0.086 & 0.000 & 0.000 & 0.000 & 0.000 & 0.000 & 0.000 & 0.000 & 0.000 & 0.000 \\
\hline stddv & & 0.153 & 0.166 & 0.019 & 0.000 & 0.000 & 0.046 & 0.017 & 0.000 & 0.000 & 0.000 \\
\hline debt/income & mean & 0.202 & 0.228 & 0.106 & 0.000 & 0.000 & 0.101 & 0.136 & 0.000 & 0.000 & 0.000 \\
\hline (if debt >0) & median & 0.179 & 0.178 & 0.062 & 0.000 & 0.000 & 0.070 & 0.108 & 0.000 & 0.000 & 0.000 \\
\hline stddv & & 0.146 & 0.204 & 0.109 & 0.000 & 0.000 & 0.096 & 0.110 & 0.000 & 0.000 & 0.000 \\
\hline
\end{tabular}


Benchmark, but $\sigma_{\eta}=\sigma_{\epsilon}=0.075$

\begin{tabular}{|c|c|c|c|c|c|c|}
\hline & \multirow[b]{2}{*}{ age } & & & & & \\
\hline & & 30 & 40 & 50 & 60 & 70 \\
\hline holds any debt & $\%$ & 100.0 & 100.0 & 100.0 & 77.5 & 4.5 \\
\hline constrained & $\%$ & 55.6 & 29.0 & 0.6 & 0.0 & 0.0 \\
\hline avg. debt/avg. ince & & 0.851 & 1.656 & 1.399 & 0.258 & 0.005 \\
\hline ind. debt/income & mean & 0.874 & 1.752 & 1.543 & 0.371 & 0.014 \\
\hline (unconditional) & median & 0.863 & 1.710 & 1.444 & 0.265 & 0.000 \\
\hline stddv & & 0.202 & 0.434 & 0.525 & 0.399 & 0.086 \\
\hline debt/income & mean & 0.874 & 1.752 & 1.543 & 0.479 & 0.309 \\
\hline (if debt >0) & median & 0.863 & 1.710 & 1.444 & 0.372 & 0.229 \\
\hline stddv & & 0.202 & 0.434 & 0.525 & 0.392 & 0.275 \\
\hline
\end{tabular}

Benchmark, but $\delta=0.03$

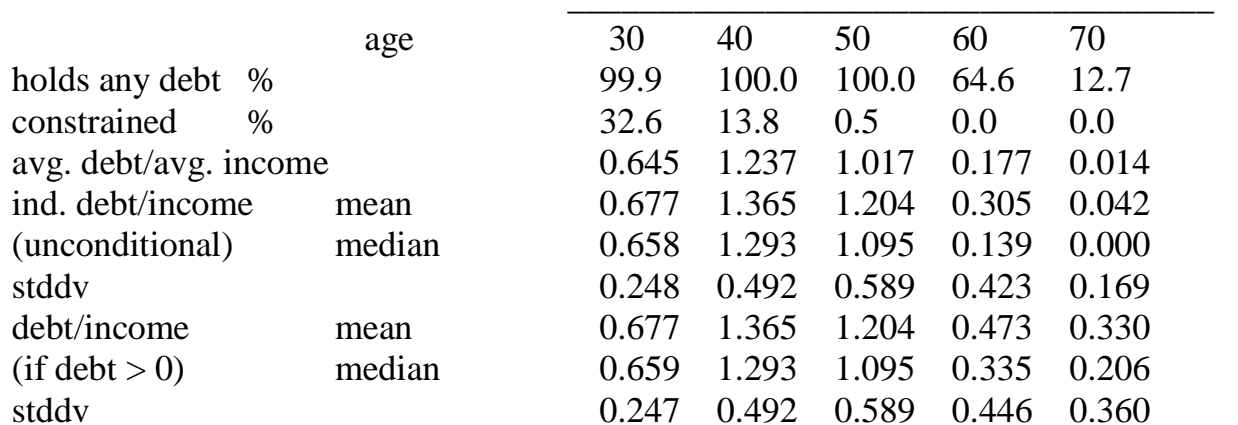

Benchmark, but $\gamma=3$

\begin{tabular}{lllll}
\hline 30 & 40 & 50 & 60 & 70 \\
12.6 & 1.0 & 0.0 & 0.0 & 0.0 \\
3.9 & 0.0 & 0.0 & 0.0 & 0.0 \\
0.011 & 0.001 & 0.000 & 0.000 & 0.000 \\
0.012 & 0.001 & 0.000 & 0.000 & 0.000 \\
0.000 & 0.000 & 0.000 & 0.000 & 0.000 \\
0.046 & 0.017 & 0.000 & 0.000 & 0.000 \\
0.097 & 0.143 & 0.000 & 0.000 & 0.000 \\
0.069 & 0.113 & 0.000 & 0.000 & 0.000 \\
0.095 & 0.102 & 0.000 & 0.000 & 0.000
\end{tabular}

Benchmark, but $R=1.03$

$\begin{array}{lllll}30 & 40 & 50 & 60 & 70 \\ 11.8 & 1.0 & 0.0 & 0.0 & 0.0 \\ 3.9 & 0.0 & 0.0 & 0.0 & 0.0 \\ 0.011 & 0.001 & 0.000 & 0.000 & 0.000 \\ 0.012 & 0.001 & 0.000 & 0.000 & 0.000 \\ 0.000 & 0.000 & 0.000 & 0.000 & 0.000 \\ 0.047 & 0.017 & 0.000 & 0.000 & 0.000 \\ 0.102 & 0.130 & 0.000 & 0.000 & 0.000 \\ 0.072 & 0.104 & 0.000 & 0.000 & 0.000 \\ 0.097 & 0.110 & 0.000 & 0.000 & 0.000\end{array}$

Note: All rows except 'constrained' based on model without liquidity constraints imposed.

'Constrained': calculated from model with liquidity constraints imposed. Constrained means: cash on hand lower than $110 \%$ of consumption. 
Table 3

Household Debt in OECD Countries

\begin{tabular}{lllll}
\hline Country & \multicolumn{2}{c}{$\begin{array}{c}\text { Liabilities } \\
\text { (percent of disposable } \\
\text { income) }\end{array}$} & $\begin{array}{c}\text { Residential Mortgage Debt } \\
\text { (percent of GDP) }\end{array}$ \\
& $\mathbf{1 9 9 5}$ & $\mathbf{2 0 0 5}$ & $\mathbf{1 9 9 2}$ & $\mathbf{2 0 0 2}$ \\
\hline Denmark & 112.9 & 155.2 & 63.9 & 74.3 \\
Netherlands & 63.4 & 134.1 & 40.0 & 78.8 \\
Portugal & 49.8 & 112.6 & 12.8 & 49.8 \\
US & 78.8 & 111.1 & 45.3 & 58.0 \\
Spain & 47.4 & 93.5 & 11.9 & 32.3 \\
Germany & 74.3 & 83.2 & 38.7 & 54.0 \\
Sweden & 54.7 & 78.3 & 37.5 & 40.4 \\
France & 47.8 & 65.2 & 21.0 & 22.8 \\
Finland & 47.2 & 58.6 & 37.2 & 31.8 \\
Belgium & 45.7 & 54.2 & 19.9 & 27.9 \\
Greece & 8.6 & 44.9 & 4.0 & 13.9 \\
Italy & 24.6 & 43.1 & 6.3 & 11.4 \\
& & & & \\
Japan & na & na & 25.3 & 36.8 \\
Ireland & na & na & 20.5 & 36.5 \\
Luxembourg & na & na & 23.9 & 17.5 \\
& & & &
\end{tabular}

(1) Calculated from OECD Financial Accounts Table IIIb Balance Sheets and from OECD National Accounts, Table 3. Disposable income is net national disposable income. Households include non-profit institutions serving households.

(2) OECD June 2004/2 No 76 December. 
Table 4a

Incidence of Household Debt Holdings by Type of Debt (Percentage of Households that Possess each type)

\begin{tabular}{|c|c|c|c|c|c|c|c|c|c|c|c|c|}
\hline \multicolumn{4}{|c|}{ Mortgage Debt } & \multirow[b]{2}{*}{ US } & \multicolumn{4}{|c|}{ Other debt } & \multicolumn{4}{|c|}{ Total } \\
\hline & Netherlands & Italy & Spain & & Netherlands & Italy & Spain & US & Netherlands & Italy & Spain & US \\
\hline 1991 & & 11.0 & & & & 14.1 & & & & 23.0 & & \\
\hline 1992 & & & & 41.7 & & & & 64.7 & & & & 73.5 \\
\hline 1993 & 40.7 & 12.5 & & & 46.1 & 15.0 & & & 64.9 & 25.1 & & \\
\hline 1994 & 39.3 & & & & 43.6 & & & & 64.1 & & & \\
\hline 1995 & 41.2 & 13.4 & & 43.4 & 43.0 & 14.1 & & 66.2 & 64.5 & 24.6 & & 74.7 \\
\hline 1996 & 42.8 & & & & 44.1 & & & & 66.4 & & & \\
\hline 1997 & 43.4 & & & & 43.8 & & & & 66.4 & & & \\
\hline 1998 & 43.1 & 9.1 & & 45.3 & 43.1 & 16.4 & & 63.7 & 66.6 & 22.9 & & 74.3 \\
\hline 1999 & 42.7 & & & & 42.6 & & & & 67.3 & & & \\
\hline 2000 & 43.7 & 9.2 & & & 44.3 & 16.5 & & & 67.3 & 23.1 & & \\
\hline 2001 & 42.7 & & & 46.6 & 40.0 & & & 64.2 & 65.3 & & & 75.5 \\
\hline 2002 & 43.7 & 10.2 & 26.7 & & 43.0 & 13.9 & 24.4 & & 67.9 & 21.4 & 43.6 & \\
\hline 2003 & 41.4 & & & & 42.2 & & & & 66.7 & & & \\
\hline 2004 & 42.9 & 11.9 & & 49.3 & 37.8 & 15.0 & & 65.8 & 66.3 & 23.5 & & 76.7 \\
\hline 2005 & 43.1 & & & & 31.1 & & & & 61.4 & & & \\
\hline 2006 & 41.8 & & & & 29.6 & & & & 59.7 & & & \\
\hline
\end{tabular}

Italy (SHIW): Figures for mortgages are debt outstanding to purchase or restructuring of buildings only and so may underestimate the total debt outstanding on mortgages. Figures for other debt and total exclude debt owed to relatives and friends. US (SCF): Figures for mortgages include mortgages, home equity loans and home equity lines of credit on the principal residence, loans on other residential property and debt on non-residential real estate. Netherlands (DHS): Figures for mortgages include all types of debt on residential and non-residential real estate.

Spain (EFF): Figures for mortgages include mortgages and other types of loans to buy the household's main residence and mortgages and other loans to buy other real estate.

All values use sampling weights. 
Table 4b

Mean Household Debt Holdings by Type of Debt (1992 Euros)

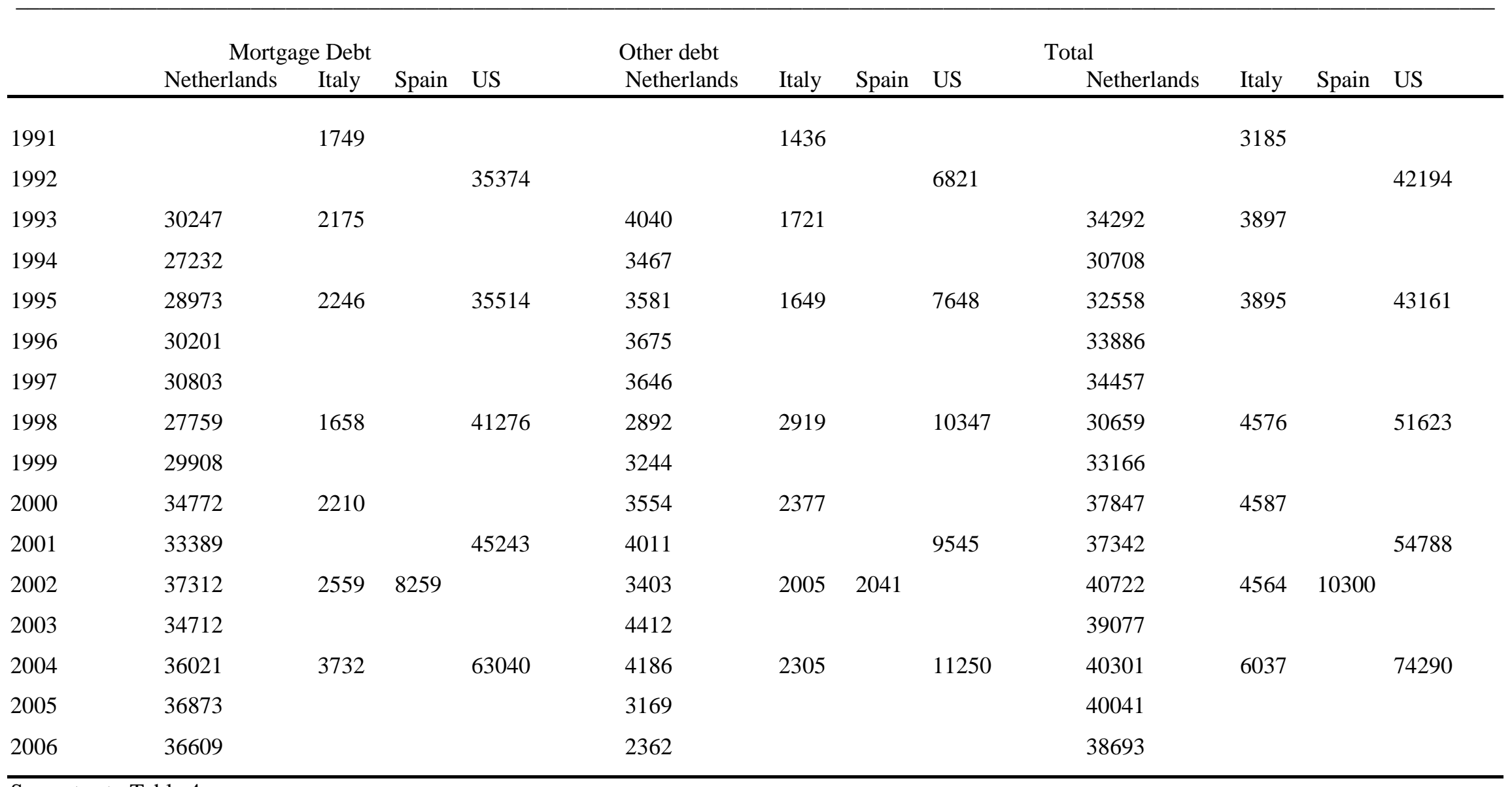

See notes to Table 4a. 
Table 4c

Median Household Debt Holdings by Type of Debt (1992 Euros) Conditional on Holding Debt

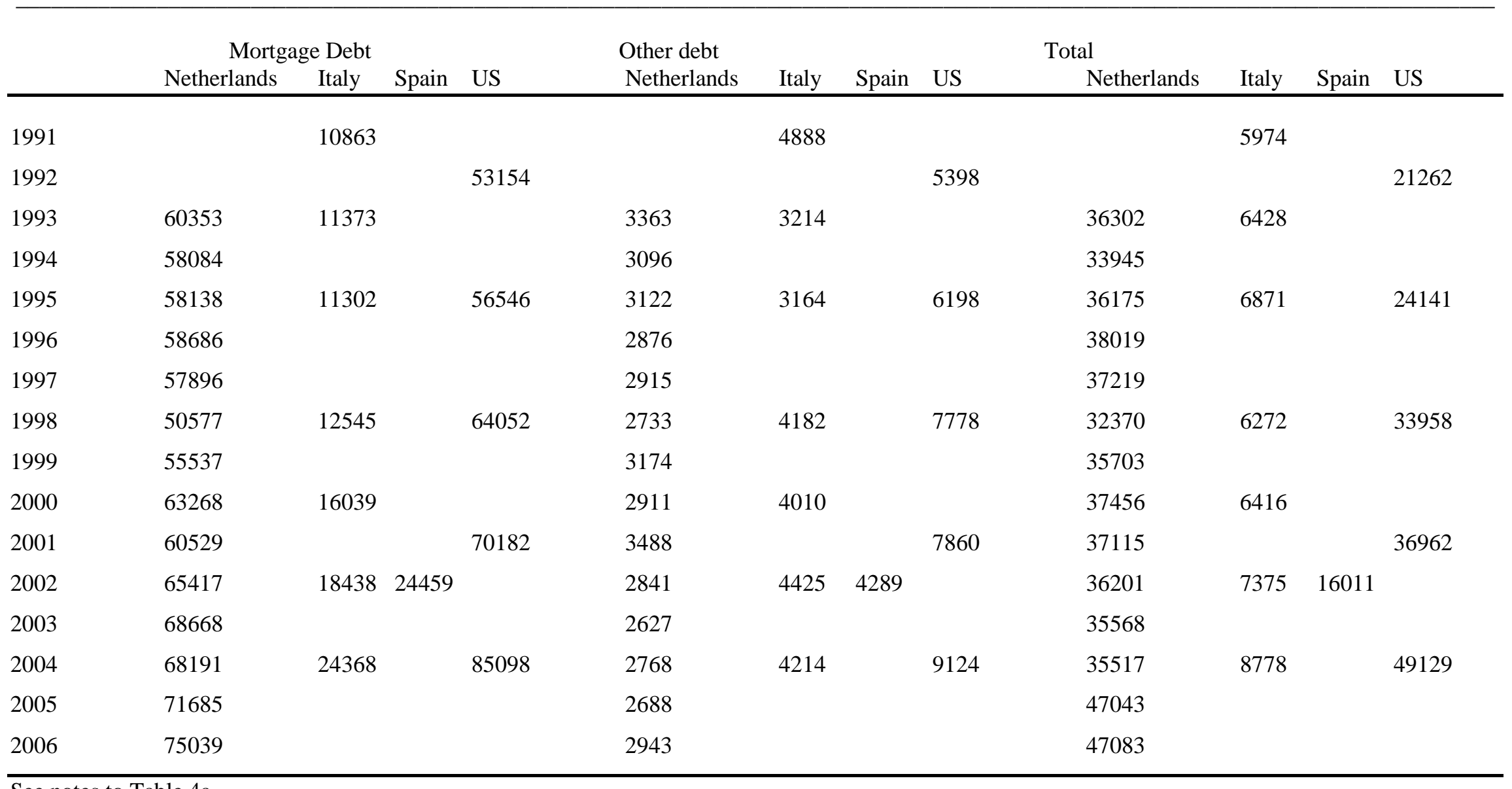

See notes to Table $4 a$. 


\section{Table 5 Constrained Households}

\begin{tabular}{|c|c|c|c|c|c|c|c|c|c|c|c|c|c|c|c|c|}
\hline & \multicolumn{4}{|c|}{ Percentage who Apply ${ }^{(1)}$} & \multicolumn{4}{|c|}{$\begin{array}{l}\text { Percentage who are rejected } \\
(1)(3)\end{array}$} & \multicolumn{3}{|c|}{$\begin{array}{l}\text { Percentage who are rejected } \\
\text { or discouraged }^{(1)(3)}\end{array}$} & \multicolumn{5}{|c|}{$\begin{array}{l}\text { Percentage who are rejected } \\
\text { conditional on application }\end{array}$} \\
\hline & Netherlands & Italy & Spain & US & Netherlands & Italy & Spain & US & Netherlands & Italy & Spain & US & Netherlands & Italy & Spain & US \\
\hline 1991 & & & & & & 0.9 & & & & 3.3 & & & & & & \\
\hline 1992 & & & & & & & & 22.5 & & & & 27.8 & & & & \\
\hline 1993 & 22.4 & & & & 0.8 & 1.1 & & & 2.4 & 3.0 & & & 4.2 & & & \\
\hline 1995 & 19.8 & 5.6 & & 63.6 & 0.9 & 0.9 & & 20.4 & 2.9 & 2.3 & & 28.6 & 4.5 & 16.2 & & 32.0 \\
\hline 1998 & 21.2 & 6.0 & & 63.6 & 0.8 & 0.5 & & 21.8 & 3.1 & 2.8 & & 28.4 & 3.9 & 7.7 & & 34.2 \\
\hline 2000 & 25.7 & 5.4 & & & 1.7 & 0.4 & & & 2.8 & 1.7 & & & 4.3 & 8.0 & & \\
\hline 2001 & 26.1 & & & 64.9 & 1.5 & & & 19.9 & 2.3 & & & 26.9 & 3.7 & & & 30.7 \\
\hline 2002 & 24.9 & 4.2 & 20.8 & & 2.5 & 0.5 & 1.1 & & 3.5 & 2.2 & 3.4 & & 9.1 & 11.7 & 5.1 & \\
\hline 2004 & 20.9 & 4.7 & & 68.7 & 1.7 & 0.6 & & 20.9 & 2.9 & 2.7 & & 27.8 & 4.5 & 11.9 & & 30.5 \\
\hline 2006 & 23.8 & & & & 2.7 & & & & 3.7 & & & & 9.4 & & & \\
\hline
\end{tabular}

All values are weighted proportions

(1) denominator is all households.

(2) denominator is all households that applied.

(3) those who were rejected or who gained only part of the amount they applied for. Those who were not rejected, or who did not gain only part of the amount they applied for, may not have applied for credit.

Time periods covered: Netherlands and Spain: any time in the two years preceding the survey, Italy: any time during the year preceding survey year, US: any time during the five years preceding the survey year. In the US and in the Netherlands it is possible for a household to have applied for credit and to have been discouraged; in Italy the questionnaire does not allow for this: a household may only be discouraged if it did not apply. 
Table 6a

Demographics Conditional On Debt Holding (Mean values or Percentages)

\begin{tabular}{|c|c|c|c|c|c|c|c|c|}
\hline & \multicolumn{3}{|c|}{ Netherlands } & \multicolumn{4}{|c|}{ Italy } & \multirow{2}{*}{$\begin{array}{l}\text { Spain } \\
2002\end{array}$} \\
\hline & 1993 & 1998 & 2003 & 1991 & 1995 & 2000 & 2004 & \\
\hline Age & 44.10 & 48.82 & 47.24 & 46.01 & 46.06 & 44.91 & 45.06 & 45.01 \\
\hline Family size & 2.64 & 2.61 & 2.39 & 3.48 & 3.44 & 3.22 & 3.08 & 3.37 \\
\hline Paid job (\%) & 68.9 & 59.9 & 63.4 & 59.6 & 50.2 & 55.4 & 63.1 & 57.2 \\
\hline Unemployed (\%) & 2.8 & 2.7 & 3.6 & 3.7 & 3.3 & 0.76 & 0.53 & 7.2 \\
\hline Retired $(\%)$ & 11.2 & 19.0 & 16.2 & 13.8 & 12.7 & 12.3 & 11.9 & 8.7 \\
\hline No paid job (\%) & 5.2 & 3.3 & 4.1 & 0.03 & 3.0 & 0.57 & 0.31 & 10.9 \\
\hline Disabled (\%) & 3.2 & 5.9 & 8.1 & 1.9 & 3.7 & 1.4 & 1.4 & 2.3 \\
\hline Other job (\%) & 3.2 & 4.3 & 1.0 & 0.18 & 0 & 0.04 & 0 & 0.26 \\
\hline Self employed (\%) & 5.3 & 5.1 & 3.8 & 24.1 & 27.0 & 29.5 & 22.8 & 13.4 \\
\hline Single $(\%)$ & 12.5 & 16.6 & 19.0 & 5.5 & 4.9 & 13.8 & 14.9 & 9.9 \\
\hline Divorced (\%) & 9.4 & 11.3 & 11.2 & 8.4 & 9.5 & 9.4 & 11.5 & 6.0 \\
\hline Married (\%) & 78.1 & 72.1 & 69.3 & 86.1 & 85.6 & 76.8 & 73.6 & 84.1 \\
\hline Female $(\%)$ & 18.7 & 15.8 & 24.5 & 10.6 & 15.0 & 18.4 & 18.5 & 28.2 \\
\hline Number of kids & 0.824 & 0.838 & 0.685 & 1.48 & 1.45 & 1.28 & 1.19 & 1.35 \\
\hline Education1 (\%) & 1.7 & 1.8 & 1.2 & na & & & & na \\
\hline Education $2(\%)$ & 7.1 & 4.5 & 4.3 & 26.9 & 24.4 & 15.1 & 12.5 & 27.0 \\
\hline Education3 (\%) & 23.0 & 19.8 & 22.4 & 33.9 & 34.2 & 33.7 & 30.6 & 16.0 \\
\hline Education4 (\%) & 17.5 & 13.2 & 13.0 & 30.9 & 32.9 & 40.2 & 45.4 & 14.9 \\
\hline Education $5(\%)$ & 9.7 & 21.3 & 17.4 & na & & & & 23.4 \\
\hline Education $6(\%)$ & 41.1 & 39.4 & 41.7 & 8.2 & 8.5 & 11.0 & 11.6 & 18.7 \\
\hline Total income & 27117 & 23471 & 22042 & 24700 & 23506 & 25565 & 24990 & 20798 \\
\hline Net Worth & 102438 & 106502 & 110548 & 152237 & 166728 & 171525 & 182639 & 177594 \\
\hline
\end{tabular}


Table 6a (contd)

Demographics Conditional On Debt Holding (Mean values or Percentages)

\begin{tabular}{|c|c|c|c|c|c|}
\hline & & & US & & \\
\hline & 1992 & 1995 & 1998 & 2001 & 2004 \\
\hline Age & 44.92 & 44.86 & 45.07 & 45.67 & 46.90 \\
\hline Family size & 2.72 & 2.66 & 2.71 & 2.67 & 2.62 \\
\hline Paid job (\%) & 63.2 & 67.2 & 68.4 & 68.9 & 66.7 \\
\hline Unemployed $(\%)$ & 5.5 & 3.5 & 2.9 & 2.0 & 2.7 \\
\hline Retired (\%) & 10.8 & 10.3 & 10.3 & 10.2 & 11.7 \\
\hline No paid job (\%) & 3.1 & 2.5 & 1.7 & 1.8 & 1.4 \\
\hline Disabled (\%) & 4.6 & 3.5 & 3.5 & 4.1 & 4.6 \\
\hline Other job (\%) & 0.11 & 1.9 & 0.47 & 0.23 & 0.46 \\
\hline Self employed $(\%)$ & 12.4 & 11.1 & 12.7 & 12.9 & 12.5 \\
\hline Single $(\%)$ & 16.4 & 17.0 & 16.5 & 15.4 & 16.7 \\
\hline Divorced (\%) & 20.0 & 19.2 & 18.1 & 18.7 & 20.7 \\
\hline Married (\%) & 64.0 & 63.8 & 65.4 & 65.9 & 62.8 \\
\hline Female $(\%)$ & 23.3 & 24.4 & 22.3 & 22.5 & 24.7 \\
\hline Number of kids & 0.82 & 0.79 & 0.82 & 0.79 & 0.76 \\
\hline Education1 & na & & & & \\
\hline Education2 (\%) & 3.4 & 2.2 & 2.5 & 2.7 & 1.9 \\
\hline Education3 (\%) & 3.8 & 3.6 & 2.3 & 2.8 & 2.2 \\
\hline Education4 (\%) & 37.4 & 39.8 & 40.5 & 39.2 & 36.6 \\
\hline Education $5(\%)$ & 19.6 & 20.4 & 16.7 & 17.9 & 19.1 \\
\hline Education $6(\%)$ & 35.9 & 34.0 & 38.0 & 37.4 & 40.2 \\
\hline Total Income & 53351 & 53496 & 61097 & 70689 & 66590 \\
\hline Net worth & 221370 & 222791 & 288453 & 352311 & 364889 \\
\hline
\end{tabular}


Table 6b

Demographics All Cases

(Mean values or Percentages)

\begin{tabular}{|c|c|c|c|c|c|c|c|c|}
\hline & & Nether & & & & aly & & Spain \\
\hline & 1993 & 1998 & 2003 & 1991 & 1995 & 2000 & 2004 & 2002 \\
\hline$\overline{\text { Age }}$ & 46.12 & 49.23 & 48.32 & 52.44 & 54.03 & 53.17 & 53.80 & 52.53 \\
\hline Family size & 2.44 & 2.42 & 2.29 & 3.06 & 2.89 & 2.71 & 2.58 & 2.94 \\
\hline Paid job $(\%)$ & 58.8 & 57.2 & 60.9 & 48.4 & 36.1 & 44.1 & 46.4 & 41.9 \\
\hline Unemployed (\%) & 3.2 & 2.9 & 2.6 & 1.0 & 3.9 & 1.5 & 1.17 & 6.1 \\
\hline Retired $(\%)$ & 18.1 & 21.5 & 17.9 & 30.4 & 32.1 & 29.7 & 30.5 & 23.0 \\
\hline No paid job (\%) & 7.2 & 5.1 & 5.6 & 0.23 & 3.4 & 1.7 & 1.7 & 15.5 \\
\hline Disabled $(\%)$ & 4.3 & 5.2 & 7.9 & 6.9 & 10.3 & 8.5 & 7.0 & 3.0 \\
\hline Other job (\%) & 4.1 & 5.1 & 1.8 & 0.25 & 0.01 & 0.09 & 0 & 0.35 \\
\hline Self employed (\%) & 4.7 & 4.4 & 3.8 & 12.7 & 14.1 & 14.4 & 13.2 & 10.2 \\
\hline Single $(\%)$ & 16.9 & 20.5 & 22.2 & 6.8 & 8.4 & 16.4 & 17.4 & 14.2 \\
\hline Divorced (\%) & 13.5 & 15.1 & 12.7 & 17.5 & 20.7 & 19.9 & 23.2 & 14.6 \\
\hline Married (\%) & 69.6 & 64.4 & 65.1 & 75.7 & 70.8 & 63.7 & 59.4 & 71.2 \\
\hline Female $(\%)$ & 23.4 & 20.2 & 26.0 & 19.0 & 27.9 & 28.2 & 30.2 & 33.9 \\
\hline Number of kids & 0.709 & 0.722 & 0.631 & 1.17 & 1.05 & 0.916 & 0.821 & 1.04 \\
\hline Education1 & 2.2 & 2.8 & 1.2 & na & & & & na \\
\hline Education $2(\%)$ & 9.5 & 4.9 & 5.3 & 43.6 & 43.0 & 33.4 & 30.3 & 41.1 \\
\hline Education3 (\%) & 28.5 & 23.4 & 23.6 & 25.8 & 26.9 & 27.6 & 28.8 & 15.1 \\
\hline Education4 (\%) & 16.0 & 13.2 & 12.6 & 23.4 & 23.7 & 29.8 & 31.7 & 11.2 \\
\hline Education $5(\%)$ & 9.8 & 18.8 & 17.9 & na & & & & 17.6 \\
\hline Education $6(\%)$ & 34.0 & 36.8 & 39.5 & 7.2 & 6.4 & 9.1 & 9.1 & 15.1 \\
\hline Total income ${ }^{(1)}$ & 23212 & 21434 & 20924 & 21097 & 19354 & 20260 & 20706 & 16934 \\
\hline Net Worth & 88602 & 93137 & 100130 & 118133 & 126769 & 140208 & 154246 & 168543 \\
\hline
\end{tabular}

${ }^{11}$ Total income relates to the following years: NL: previous year; Italy: year as indicated, US and Spain: previous year.

All monetary values in 1992 Euros. NL: income is total net household income, Italy: income is net disposable income, US and Spain: gross income.

For education categories, refer to Data Appendix. Sampling weights used. 
Table 6b (contd)

Demographics All Cases

(Mean values or Percentages)

\begin{tabular}{|c|c|c|c|c|c|}
\hline & & & US & & \\
\hline & 1992 & 1995 & 1998 & 2001 & 2004 \\
\hline Age & 48.43 & 48.45 & 48.73 & 48.97 & 49.56 \\
\hline Family size & 2.50 & 2.49 & 2.50 & 2.49 & 2.46 \\
\hline Paid job (\%) & 54.0 & 57.1 & 58.5 & 59.95 & 59.26 \\
\hline Unemployed (\%) & 5.6 & 4.1 & 3.4 & 2.6 & 2.9 \\
\hline Retired $(\%)$ & 18.1 & 17.9 & 18.9 & 17.9 & 18.0 \\
\hline No paid job (\%) & 5.4 & 3.5 & 2.6 & 2.5 & 2.1 \\
\hline Disabled (\%) & 5.7 & 4.3 & 5.0 & 5.0 & 5.6 \\
\hline Other job $(\%)$ & 0.08 & 3.0 & 0.40 & 0.27 & 0.55 \\
\hline Self employed (\%) & 10.6 & 10.1 & 11.1 & 11.8 & 11.6 \\
\hline Single $(\%)$ & 18.0 & 17.8 & 18.6 & 17.2 & 18.0 \\
\hline Divorced (\%) & 24.5 & 23.6 & 22.8 & 22.2 & 24.2 \\
\hline Married (\%) & 57.5 & 58.5 & 58.6 & 60.5 & 57.8 \\
\hline Female $(\%)$ & 27.8 & 28.8 & 27.9 & 26.7 & 28.1 \\
\hline Number of kids & 0.70 & 0.69 & 0.69 & 0.69 & 0.67 \\
\hline Education 1 & na & & & & \\
\hline Education2 (\%) & 4.3 & 3.2 & 3.4 & 3.3 & 3.3 \\
\hline Education3 (\%) & 6.0 & 5.7 & 3.7 & 4.3 & 3.5 \\
\hline Education4 (\%) & 38.8 & 41.0 & 41.9 & 40.0 & 37.7 \\
\hline Education 5 & 19.1 & 19.3 & 17.7 & 18.3 & 19.0 \\
\hline Education $6(\%)$ & 31.7 & 30.8 & 33.3 & 34.2 & 36.5 \\
\hline Total Income & 47409 & 48919 & 54119 & 64842 & 61695 \\
\hline Net worth & 217401 & 234510 & 284250 & 371996 & 385383 \\
\hline
\end{tabular}


Table 7

The Credit Application and Granting Decisions

\begin{tabular}{llllllll}
\hline $\begin{array}{l}\text { Desired } \\
\text { Holding/ }\end{array}$ & $\begin{array}{l}\text { Wants } \\
\text { Flow }\end{array}$ & $\begin{array}{l}\text { Discour } \\
\text { nged }\end{array}$ & Applies & Rejected & $\begin{array}{l}\text { Observed } \\
\text { Holding/ } \\
\text { Flow }\end{array}$ & $\begin{array}{l}\text { Stock } \\
\text { Sties to }\end{array}$ \\
\hline $\mathrm{d}>0$ & yes & no & yes & no & d $>0$ & yes & yes \\
$\mathrm{d}>0$ & yes & no & yes & yes & 0 & yes & yes \\
$\mathrm{d}>0$ & yes & yes & no & na & 0 & yes & yes \\
0 & no & na & no & na & 0 & yes & yes \\
$\mathrm{d}<0$ & yes & na & na & na & 0 & yes & no \\
$\mathrm{d}<0$ & yes & na & na & na & d $<0$ & no & yes \\
\hline
\end{tabular}


Table 8

Probability of Applying for a Loan

Marginal Effects

\begin{tabular}{|c|c|c|c|c|}
\hline & $\begin{array}{l}\text { Netherlands } \\
\text { Random Effects }\end{array}$ & $\begin{array}{l}\text { Italy } \\
\text { Random Effects }\end{array}$ & $\begin{array}{l}\text { US } \\
\text { Pooled }\end{array}$ & $\begin{array}{l}\text { Spain } \\
2002\end{array}$ \\
\hline wealth & $-0.0061 * \star$ & $-0.0030 * \star$ & $-0.0025^{\star}$ & $-0.0172 * \star$ \\
\hline income 1 & 0.0138 & 0.0033 & $0.0212 * *$ & 0.0341 \\
\hline income 2 & $0.1253 *$ & $0.0514 * \star$ & $0.3083 * \star$ & $0.1089 *$ \\
\hline income 3 & 0.1128 & -0.0311 & 0.0855 & 0.0904 \\
\hline income 4 & 0.1220 & 0.0209 & 0.0475 & 0.0915 \\
\hline income 5 & 0.1127 & 0.0234 & $-0.0751 \star \star$ & 0.0262 \\
\hline income 6 & $0.0545 \star$ & 0.0080 & $-0.0343 * \star$ & 0.0293 \\
\hline inc-perm inc & $-0.0021 \star \star$ & 0.0001 & 0.0006 & -0.0016 \\
\hline age $<30$ & 0.0078 & -0.0006 & -0.0056 & -0.0026 \\
\hline $30=$ age $<40$ & $-0.0072 * \star$ & 0.0002 & -0.0044 & $-0.0076 * \star$ \\
\hline $40=$ age $<50$ & $-0.0068 * \star$ & $-0.0010 \star$ & $-0.0072 \star \star$ & 0.0002 \\
\hline $50=$ age $<65$ & $-0.0084 \star \star$ & $-0.0018 * \star$ & $-0.0122 \star \star$ & $-0.0038 * \star$ \\
\hline $65=$ age & $-0.0076 \star \star$ & $-0.0023 * *$ & $-0.0194 * \star$ & $-0.0100 * *$ \\
\hline ed1 & -0.0255 & na & na & na \\
\hline ed3 & 0.0025 & 0.0008 & -0.0408 & -0.0008 \\
\hline ed 4 & 0.0238 & -0.0003 & 0.0328 & -0.0098 \\
\hline ed5 & 0.0185 & na & $0.0620 *$ & 0.0021 \\
\hline ed 6 & 0.0032 & -0.0021 & $0.0627 *$ & -0.0261 \\
\hline no kids $<=6$ yrs & -0.0057 & 0.0036 & -0.0080 & 0.0086 \\
\hline no kids $7-12$ & 0.0013 & $0.0066 * *$ & -0.0066 & 0.0192 \\
\hline no kids 13-19 & -0.0017 & $0.0067 * *$ & 0.0131 & 0.0144 \\
\hline no kids $20+$ & 0.0069 & $0.0062 * \star$ & 0.0088 & $0.0235 * \star$ \\
\hline unemployed & $-0.0486 \star$ & 0.0003 & $-0.1724 \star \star$ & $0.0446 *$ \\
\hline no paid job & $-0.0618 \star \star$ & -0.0107 & $-0.1285 \star \star$ & 0.0246 \\
\hline retired & -0.0080 & 0.0082 & $-0.0686 * *$ & -0.0060 \\
\hline disabled & -0.0344 & -0.0072 & $-0.1393 * \star$ & -0.0060 \\
\hline otherjob & -0.0374 & -0.0255 & -0.0465 & 0.1560 \\
\hline selfemployed & 0.0040 & 0.0035 & 0.0085 & 0.0021 \\
\hline female & -0.0120 & 0.0012 & -0.0278 & $-0.0310 \star$ \\
\hline single & $-0.1009 \star \star$ & -0.0051 & $-0.0784 \star \star$ & $-0.0379 \star \star$ \\
\hline divorced/wid & -0.0161 & 0.0043 & 0.0127 & -0.0172 \\
\hline single parent & 0.0294 & -0.0085 & $-0.0899 * \star$ & $0.0562 \star$ \\
\hline Nobs & 18,912 & 20,230 & 12540 & 5087 \\
\hline Rho & $0.427 \quad 1087.73$ & $0.189 \quad 60.25$ & & \\
\hline Pseudo $\mathrm{R}^{2}$ & & & .180 & 0.136 \\
\hline
\end{tabular}

Rho $=\sigma_{u}^{2} /\left(\sigma_{u}^{2}+1\right)$ random effects variance as fraction of total error variance; test statistic is chi-squared.

Notes for Netherlands and Italy: Regional dummies included, but not reported.

Notes for United States: Sample is for years 1995, 1998 \& 2001.

Notes for Italy: Sample is all households for which observations existed in at least two adjacent surveys (1995 \& 1998 or 2000 \& 1998 or 2000 \& 2002 or $2002 \& 2004$ ).

Notes for all countries: intercept and time effects included but not reported. Excluded categories: education: level 2 ( level 1 not available for Italy, US or Spain and level 5 also not available for Italy); marital status: married; occupational status: paid job. Income: linear spline; all money values in 1992 Euros.

Income, wealth and (income - permanent income) are $\ln (x+1)$ if $x \geq 0,-\ln (-x+1)$ if $x<0$.

$*$ denotes significance at $5 \%, * *$ denotes significance at $1 \%$. 


\section{Table 9a \\ Credit Constraint Equations Models (Probits) Rejected or gained only part of amount applied for, conditional on application}

\section{Marginal Effects}

\begin{tabular}{|c|c|c|c|}
\hline & $\begin{array}{l}\text { Netherlands } \\
\text { Random Effects }\end{array}$ & $\begin{array}{l}\text { Italy } \\
\text { Random Effects }\end{array}$ & $\begin{array}{l}\text { US } \\
\text { Pooled }\end{array}$ \\
\hline wealth & $-0.0008 * \star$ & $-9.33 * 10^{-6}$ & $-0.0091 * \star$ \\
\hline income 1 & 0.0055 & -0.0230 & 0.0087 \\
\hline income 2 & -0.0062 & $-0.1407 \star \star$ & -0.0656 \\
\hline income 3 & -0.0492 & -0.0214 & $-0.1435 * \star$ \\
\hline income 4 & -0.0148 & -0.1278 & $-0.2121 * \star$ \\
\hline income 5 & 0.0121 & -0.0007 & $-0.0816 * \star$ \\
\hline income 6 & -0.0283 & -0.1115 & -0.0089 \\
\hline inc-perm inc & 0.0005 & $0.0028 * *$ & $0.0049 * *$ \\
\hline age $<30$ & 0.0011 & 0.0040 & -0.0020 \\
\hline $30=$ age $<40$ & -0.0007 & 0.0012 & $-0.0098 * *$ \\
\hline $40=$ age $<50$ & 0.0011 & 0.0014 & -0.0005 \\
\hline $50=$ age $<65$ & $-0.0013 *$ & 0.0010 & -0.0003 \\
\hline $65=$ age & -0.0004 & 0.0024 & $-0.0069 \star$ \\
\hline ed1 & 0.0164 & na & na \\
\hline ed3 & -0.0022 & 0.0138 & 0.0792 \\
\hline ed4 & 0.0060 & -0.0035 & $0.1679 * \star$ \\
\hline ed5 & 0.0020 & -0.0037 & $0.1796 * \star$ \\
\hline ed 6 & -0.0038 & & $0.1364 * \star$ \\
\hline no kids $<=6$ yrs & 0.0035 & 0.0139 & 0.0129 \\
\hline no kids $7-12$ & -0.0030 & $0.0269 * *$ & $0.0336 * *$ \\
\hline no kids $13-19$ & -0.0004 & 0.0088 & $0.0414 * *$ \\
\hline no kids $20+$ & 0.0037 & 0.0115 & -0.0171 \\
\hline unemployed & 0.0217 & 0.0847 & -0.0242 \\
\hline no paid job & $0.0457 * \star$ & 0.0247 & $-0.1016 \star \star$ \\
\hline retired & 0.0021 & -0.0082 & $-0.0821 * \star$ \\
\hline disabled & $0.0798 * *$ & -0.0047 & $0.0864 *$ \\
\hline otherjob & $0.0335 *$ & & 0.0001 \\
\hline selfemployed & 0.0136 & 0.0039 & 0.0239 \\
\hline female & 0.0031 & -0.0018 & $-0.0384 *$ \\
\hline single & -0.0007 & $0.1546 * \star$ & 0.0036 \\
\hline divorced/wid & 0.0015 & 0.0138 & 0.0344 \\
\hline single parent & -0.0057 & -0.0244 & $0.0674 *$ \\
\hline Nobs & 4571 & 1089 & 8109 \\
\hline Rho & $0.276 \quad 35.63$ & 0.228 & \\
\hline Pseudo R2 & & & 0.132 \\
\hline
\end{tabular}

Note for Italy: Sample is all household-years for which observations were available in at least 2 adjacent years ( $1995 \& 1998$ or $1998 \& 2000$ or $2000 \& 2002$ or $2002 \& 2004)$ and the household applied for credit in that questionnaire year. Since very few households indicated they applied in two successive questionnaires, the mean number of year observations per household is only 1.2.

Note for US: Sample is for households from surveys in 1995, 1998 \& 2001 that applied for credit.

Notes for all countries: intercept and time effects included but not reported. Excluded categories: education: level 2 ( level 1 not available for Italy, US or Spain and level 5 also not available for Italy); marital status: married; occupational status: paid job. Income: linear spline; all money values in 1992 Euros.

Income, wealth and (income - permanent income) are $\ln (x+1)$ if $x \geq 0,-\ln (-x+1)$ if $x<0$.

$*$ denotes significance at $5 \%, * *$ denotes significance at $1 \%$. 


\section{Table 9b \\ Credit Constraint Equations Models (Probits) \\ Rejected Or Gained Only Part Of Amount Applied For Conditional On Application, Or Discouraged Conditional On Not Applying}

Marginal Effects

\begin{tabular}{|c|c|c|c|c|}
\hline & $\begin{array}{l}\text { Netherlands } \\
\text { Random Effects }\end{array}$ & $\begin{array}{l}\text { Italy } \\
\text { Random Effects }\end{array}$ & $\begin{array}{l}\text { US } \\
\text { Pooled }\end{array}$ & $\begin{array}{l}\text { Spain } \\
2002\end{array}$ \\
\hline wealth & $-0.0004 * \star$ & $-0.0011 \star \star$ & $-0.0080 * \star$ & $-0.0033 * \star$ \\
\hline income 1 & 0.0007 & 0.0011 & 0.0044 & -0.0067 \\
\hline income 2 & $-0.0093 *$ & -0.0028 & 0.0006 & -0.0109 \\
\hline income 3 & -0.0175 & -0.0129 & $-0.1111 * \star$ & 0.0018 \\
\hline income 4 & 0.0006 & -0.0096 & $-0.1405 * \star$ & -0.0011 \\
\hline income 5 & 0.0082 & 0.0056 & $-0.0663 * *$ & -0.0164 \\
\hline income 6 & -0.0057 & -0.0079 & -0.0128 & -0.0070 \\
\hline inc-perm inc & $0.0002 * \star$ & $0.0003 * \star$ & $0.0033 * \star$ & -0.0004 \\
\hline age $<30$ & 0.0003 & -0.0002 & -0.0022 & -0.0015 \\
\hline $30=$ age $<40$ & $-0.0004 *$ & 0.0003 & $-0.0078 * \star$ & 0.0001 \\
\hline $40=$ age $<50$ & 0.0002 & $-0.0006 *$ & -0.0016 & 0.0000 \\
\hline $50=$ age $<65$ & $-0.0004 * \star$ & -0.0002 & $-0.0036 * \star$ & -0.0002 \\
\hline $65=$ age & -0.0003 & $-0.0008 * \star$ & $-0.0116 * \star$ & -0.0003 \\
\hline ed1 & -0.0010 & na & na & na \\
\hline ed3 & -0.0016 & 0.0048 & $0.0174 * \star$ & $-0.0125 * \star$ \\
\hline ed 4 & -0.0007 & -0.0034 & $0.0771 * \star$ & $-0.0124 * *$ \\
\hline ed5 & -0.0008 & na & $0.0992 * \star$ & -0.0038 \\
\hline ed6 & $-0.0041 *$ & -0.0001 & $0.0567 \star$ & $-0.0140 * \star$ \\
\hline no kids $<=6$ yrs & 0.0004 & 0.0027 & 0.0056 & 0.0030 \\
\hline no kids $7-12$ & -0.0002 & $0.0036 * *$ & $0.0252 * \star$ & 0.0016 \\
\hline no kids $13-19$ & -0.0001 & 0.0022 & $0.0342 * *$ & -0.0051 \\
\hline no kids $20+$ & 0.0001 & $0.0028 * *$ & 0.0011 & 0.0013 \\
\hline unemployed & 0.0040 & $0.0160 * *$ & -0.0255 & $0.0218 *$ \\
\hline no paid job & 0.0016 & 0.0020 & $-0.0861 * \star$ & -0.0036 \\
\hline retired & 0.0019 & 0.0029 & $-0.0658 \star \star$ & -0.0016 \\
\hline disabled & $0.0127 * \star$ & -0.0042 & 0.0151 & -0.0039 \\
\hline otherjob & $0.0069 *$ & -0.0091 & -0.0034 & -0.0035 \\
\hline selfemployed & $0.0085 * *$ & 0.0017 & 0.0182 & -0.0004 \\
\hline female & 0.0016 & -0.0014 & -0.0178 & 0.0002 \\
\hline single & $-0.0026 * \star$ & 0.0032 & -0.0101 & -0.0013 \\
\hline divorced/wid & -0.0001 & 0.0036 & $0.0267 \star$ & 0.0075 \\
\hline single parent & 0.0027 & -0.0039 & $0.0605 * *$ & 0.0065 \\
\hline Nobs & 18,896 & 20,230 & 12,540 & 5,087 \\
\hline Rho & $0.286 \quad 129.01$ & 0.19120 .20 & & \\
\hline Pseudo R2 & & & $0.170 \quad 2242$ & $0.136 \quad 158$ \\
\hline
\end{tabular}

Note for Italy: Sample is all household-years for which observations were available in at least 2 adjacent years (1995 \& 1998 or $1998 \& 2000$ or $2000 \& 2002$ or $2002 \& 2004)$.

Note for US: Sample is for households from surveys in 1995, 1998 \& 2001.

Notes for all countries: intercept and time effects included but not reported. Excluded categories: education: level 2 ( level 1 not available for Italy, US or Spain and level 5 also not available for Italy); marital status: married; occupational status: paid job. Income: linear spline; all money values in 1992 Euros.

Income, wealth and (income - permanent income) are $\ln (x+1)$ if $x \geq 0,-\ln (-x+1)$ if $x<0$.

$*$ denotes significance at $5 \%, * *$ denotes significance at $1 \%$. 
Table 9c

Credit Constraint Equations Models (Probits)

Rejected Or Gained Only Part Of Amount Applied For, Or Discouraged

Marginal Effects

\begin{tabular}{|c|c|c|}
\hline & $\begin{array}{l}\text { Netherlands } \\
\text { Random Effects }\end{array}$ & $\begin{array}{l}\text { US } \\
\text { Pooled }\end{array}$ \\
\hline wealth & $-0.0006 * \star$ & $-0.0097 * \star$ \\
\hline income 1 & 0.0016 & -0.0007 \\
\hline income 2 & -0.0083 & 0.0158 \\
\hline income 3 & $-0.0244 *$ & $-0.1623 * \star$ \\
\hline income 4 & 0.0080 & $-0.1217 * \star$ \\
\hline income 5 & 0.0067 & $-0.0698 * *$ \\
\hline income 6 & $-0.0098 *$ & 0.0003 \\
\hline inc-perm inc & $0.0002 *$ & $0.0034 * *$ \\
\hline age $<30$ & 0.0002 & -0.0013 \\
\hline $30=$ age $<40$ & -0.0004 & $-0.0077 * *$ \\
\hline $40=$ age $<50$ & 0.0002 & $-0.0036 * \star$ \\
\hline $50=$ age $<65$ & $-0.0006 * \star$ & $-0.0054 * \star$ \\
\hline $65=$ age & -0.0005 & $-0.0106 * \star$ \\
\hline ed1 & -0.0028 & na \\
\hline ed3 & -0.0015 & -0.0259 \\
\hline ed 4 & 0.0006 & $0.0523 *$ \\
\hline ed5 & -0.0007 & $0.0677 * *$ \\
\hline ed 6 & $-0.0047 *$ & 0.0328 \\
\hline no kids $<=6$ yrs & 0.0005 & 0.0040 \\
\hline no kids $7-12$ & -0.0001 & $0.0203 * *$ \\
\hline no kids $13-19$ & 0.0003 & $0.0331 * \star$ \\
\hline no kids $20+$ & 0.0005 & 0.0135 \\
\hline unemployed & 0.0042 & $-0.0368 *$ \\
\hline no paid job & 0.0014 & $-0.0996 * \star$ \\
\hline retired & 0.0028 & $-0.0712 * *$ \\
\hline disabled & $0.0175 * *$ & 0.0131 \\
\hline otherjob & $0.0095 *$ & -0.0060 \\
\hline selfemployed & $0.0093 * *$ & $0.0325 * \star$ \\
\hline female & 0.0024 & $-0.0296 * \star$ \\
\hline single & $-0.0042 \star \star$ & -0.0164 \\
\hline divorced/wid & -0.0023 & $0.0414 * \star$ \\
\hline single parent & 0.0084 * & $0.1088 * *$ \\
\hline Nobs & 19,378 & 16,260 \\
\hline Rho & $0.296 \quad 179.24$ & \\
\hline Pseudo R2 & & $0.176 \quad 3159$ \\
\hline
\end{tabular}

Note for US: Sample is for households from surveys in 1992, 1995, 1998 \& 2001.

Notes for all countries: intercept and time effects included but not reported. Excluded categories: education: level 2 ( level 1 not available for Italy, US or Spain and level 5 also not available for Italy); marital status: married; occupational status: paid job. Income: linear spline; all money values in 1992 Euros.

Income, wealth and (income - permanent income) are $\ln (x+1)$ if $x \geq 0,-\ln (-x+1)$ if $x<0$.

$*$ denotes significance at $5 \%, * *$ denotes significance at $1 \%$. 
Table 10

Debt Outstanding

\begin{tabular}{|c|c|c|c|c|c|c|c|c|c|c|}
\hline & \multicolumn{2}{|c|}{$\begin{array}{l}\text { Netherlands } \\
\text { RE Regression }\end{array}$} & \multicolumn{2}{|c|}{$\begin{array}{l}\text { Italy } \\
\text { RE Regression }\end{array}$} & \multicolumn{2}{|c|}{$\begin{array}{l}\text { US } \\
\text { Pooled OLS }\end{array}$} & \multicolumn{2}{|c|}{2 Stage Seln. } & \multicolumn{2}{|l|}{$\begin{array}{l}\text { Spain } \\
\text { Tobit }\end{array}$} \\
\hline & COEFF & z-value & COEFF & z-value & COEFF & z-value & COEFF & z-value & COEFF & z-value \\
\hline wealth & -0.029 & $-11.71 * \star$ & -0.033 & $-4.59 * *$ & -0.009 & $-2.90 * *$ & 0.010 & 1.70 & -0.127 & -1.29 \\
\hline income 1 & -0.030 & -0.61 & -0.113 & $-2.08 *$ & -0.082 & $-3.23 * \star$ & -0.075 & -1.01 & 0.276 & 0.28 \\
\hline income 2 & 0.883 & $4.99 * *$ & 0.718 & $2.64 * \star$ & 1.966 & $18.09 * *$ & 2.010 & $12.75 * \star$ & 5.746 & $2.99 * *$ \\
\hline income 3 & 1.684 & $6.29 * \star$ & 0.361 & 1.22 & 1.394 & $10.03 * *$ & 1.448 & $8.72 \star \star$ & 4.227 & 1.85 \\
\hline income 4 & 0.392 & 1.50 & 0.329 & 1.18 & 1.248 & $10.17 \star \star$ & 1.234 & $9.78 * \star$ & 0.874 & 0.39 \\
\hline income 5 & 0.555 & $3.08 * \star$ & 0.301 & 1.38 & 0.976 & $15.56 * \star$ & 0.963 & $13.64 * \star$ & 2.396 & 1.53 \\
\hline income 6 & 0.294 & $3.78 * *$ & 0.646 & $6.06 * *$ & 0.571 & $15.07 * \star$ & 0.519 & $10.36 * *$ & -0.148 & -0.24 \\
\hline inc-perm inc & -0.010 & $-4.67 * \star$ & 0.001 & 0.21 & -0.023 & $-11 \cdot 31 * \star$ & -0.021 & $-8.48 * \star$ & 0.032 & 0.96 \\
\hline age $<30$ & 0.180 & $8.81^{\star *}$ & -0.011 & -0.45 & 0.050 & $4.57 \star \star$ & 0.039 & $2.55 *$ & 0.215 & 1.05 \\
\hline $30<=$ age $<40$ & 0.024 & $2.92 \star \star$ & 0.014 & 1.52 & 0.006 & 0.82 & 0.009 & 1.11 & -0.206 & $-2.07 \star$ \\
\hline $40<=$ age $<50$ & -0.002 & -0.35 & -0.023 & $-2.95 * \star$ & -0.007 & -1.13 & -0.014 & -2.31 * & -0.195 & $-2.45 *$ \\
\hline $50<=$ age $<65$ & -0.039 & $-6.48 * *$ & -0.017 & $-2.37 *$ & -0.009 & -1.85 & -0.009 & -1.55 & -0.324 & $-5.96 * \star$ \\
\hline $65<=$ age & -0.023 & $-2.78 * \star$ & -0.011 & -1.13 & -0.055 & $-8.69 * \star$ & -0.067 & $-5.87 \star \star$ & -0.461 & $-7.37 \star \star$ \\
\hline ed1 & 0.266 & 1.53 & na & & na & & na & & & na \\
\hline ed3 & 0.226 & $2.15^{\star}$ & 0.063 & 1.07 & -0.547 & $-3.88 * \star$ & -0.517 & $-2.72 \star \star$ & -0.048 & -0.09 \\
\hline ed4 & 0.513 & $4.41^{\star *}$ & 0.326 & $5.18 * *$ & -0.194 & -1.75 & -0.217 & -1.42 & 0.350 & 0.58 \\
\hline ed5 & 0.421 & $3.67 * \star$ & na & & -0.206 & -1.81 & -0.220 & -1.39 & 0.177 & 0.32 \\
\hline ed6 & 0.682 & $6.20 * \star$ & 0.408 & $4.53 * *$ & -0.056 & -0.49 & -0.068 & -0.44 & -0.456 & -0.77 \\
\hline no kids $<=6$ yrs & 0.104 & $3.33 * *$ & -0.021 & -0.48 & 0.050 & 1.88 & 0.062 & $2.12^{\star}$ & 1.654 & $3.98 * *$ \\
\hline no kids $7-12$ & 0.039 & 1.28 & 0.026 & 0.67 & 0.043 & 1.65 & 0.059 & $2.38 \star$ & 0.978 & $2.42 \star$ \\
\hline no kids 13-19 & 0.028 & 1.00 & -0.039 & -1.16 & 0.067 & $2.67 \star \star$ & 0.058 & $2.26 *$ & -0.146 & -0.45 \\
\hline no kids $20+$ & -0.051 & -1.42 & 0.027 & 0.91 & 0.061 & 1.67 & 0.048 & 1.14 & 0.891 & $3.62 * *$ \\
\hline unemployed & -0.229 & $-2.90 * \star$ & -0.058 & -0.38 & -0.077 & -0.82 & -0.114 & -0.87 & 0.199 & 0.25 \\
\hline no paid job & 0.094 & -1.07 & -0.140 & -0.97 & -0.034 & -0.30 & 0.162 & 1.01 & -1.218 & -1.73 \\
\hline retired & -0.048 & -0.79 & 0.104 & 1.39 & -0.095 & -1.38 & -0.140 & -1.46 & -2.145 & $-3.23 * \star$ \\
\hline disabled & -0.279 & $-3.60 * *$ & -0.020 & -0.15 & 0.012 & 0.13 & 0.008 & 0.07 & -2.037 & -1.89 \\
\hline otherjob & -0.236 & $-2.97 \star \star$ & 0.448 & 1.02 & 0.096 & 0.46 & 0.163 & 0.78 & 2.072 & 0.81 \\
\hline selfemployed & 0.219 & $3.38 * *$ & 0.658 & $13.61 * *$ & 0.420 & $10.55 * *$ & 0.384 & $8.88^{* *}$ & -0.345 & -0.69 \\
\hline
\end{tabular}




\begin{tabular}{|c|c|c|c|c|c|c|c|c|c|c|}
\hline female & -0.321 & $-5.35 \star \star$ & -0.043 & -0.73 & -0.086 & -1.51 & -0.145 & $-2.08 *$ & -0.472 & -0.99 \\
\hline single & -0.852 & $-12 \cdot 78 * \star$ & -0.354 & $-4.16 * \star$ & -0.118 & -1.90 & -0.123 & -1.50 & -3.628 & $-6.12 * \star$ \\
\hline divorced/wid & -0.395 & $-5.43 * *$ & -0.118 & -1.28 & 0.063 & 1.10 & 0.071 & 1.03 & -1.754 & $-2.41 *$ \\
\hline single parent & -0.529 & $-4.86 * \star$ & -0.057 & -0.53 & -0.181 & -1.82 & -0.244 & -1.58 & 1.574 & 1.88 \\
\hline lambda 1 & & & & & & & 0.251 & 1.31 & & \\
\hline lambda 2 & & & & & & & 0.436 & $2.95 * *$ & & \\
\hline Nobs & 14018 & & 6876 & & 12218 & & 9668 & & 5087 & \\
\hline Rho & 0.763 & & 0.388 & & & & & & & \\
\hline R2 & 0.2214 & & 0.138 & & 0.4724 & & 0.4603 & & 0.092 & \\
\hline
\end{tabular}

Notes for Italy: Sam ple is all household-years for which observations were available in at least 2 adjacent years (1993 \& 1995 or $1995 \& 1998$ or 1998 \& 2000 or $2000 \& 2002$ or $2002 \& 2004)$ and that have debt $>0$ Notes for US: Equations also include the variable "white" which is not available for the Netherlands or Italy. Sample is for all households in 1992, 1995, 1998 \& 2001 surveys. Pooled estimates use sample where debt $>0.2$ stage selection estimates estimated using households that have debt $>0$ and that are not credit constrained (with selection equations).

Notes for Spain: Sample consists of all households with debt $\geq 0$. All households with debt $=0$ are regarded as censored. 